\title{
Emerging applications of bedside 3D printing in plastic surgery
}

\author{
Michael P. Chae ${ }^{1,2}$, Warren M. Rozen ${ }^{1,2}$, Paul G. McMenamin ${ }^{3}$, Michael W. Findlay ${ }^{1,4 *}$, \\ Robert T. Spychal' and David J. Hunter-Smith ${ }^{1,2}$
}

${ }^{1} 3 D$ PRINT Laboratory, Department of Surgery, Peninsula Health, Frankston, VIC, Australia, ${ }^{2}$ Monash University Plastic and Reconstructive Surgery Group (Peninsula Clinical School), Peninsula Health, Frankston, VIC, Australia, ${ }^{3}$ Department of Anatomy and Developmental Biology, Centre for Human Anatomy Education, School of Biomedical Sciences, Faculty of Medicine, Nursing and Health Sciences, Monash University, Clayton, VIC, Australia, ${ }^{4}$ Department of Surgery, Stanford University, Stanford, CA, USA

Modern imaging techniques are an essential component of preoperative planning in plastic and reconstructive surgery. However, conventional modalities, including three-dimensional (3D) reconstructions, are limited by their representation on 2D workstations. $3 \mathrm{D}$ printing, also known as rapid prototyping or additive manufacturing, was once the province of industry to fabricate models from a computer-aided design (CAD) in a layer-by-layer manner. The early adopters in clinical practice have embraced the medical imaging-guided 3D-printed biomodels for their ability to provide tactile feedback and a superior appreciation of visuospatial relationship between anatomical structures. With increasing accessibility, investigators are able to convert standard imaging data into a CAD file using various 3D reconstruction softwares and ultimately fabricate 3D models using 3D printing techniques, such as stereolithography, multijet modeling, selective laser sintering, binder jet technique, and fused deposition modeling. However, many clinicians have questioned whether the cost-to-benefit ratio justifies its ongoing use. The cost and size of 3D printers have rapidly decreased over the past decade in parallel with the expiration of key 3D printing patents. Significant improvements in clinical imaging and user-friendly 3D software have permitted computer-aided 3D modeling of anatomical structures and implants without outsourcing in many cases. These developments offer immense potential for the application of 3D printing at the bedside for a variety of clinical applications. In this review, existing uses of 3D printing in plastic surgery practice spanning the spectrum from templates for facial transplantation surgery through to the formation of bespoke craniofacial implants to optimize post-operative esthetics are described. Furthermore, we discuss the potential of 3D printing to become an essential office-based tool in plastic surgery to assist in preoperative planning, developing intraoperative guidance tools, teaching patients and surgical trainees, and producing patient-specific prosthetics in everyday surgical practice.

Keywords: 3D printing, bedside, desktop application, plastic and reconstructive surgery, cost, preoperative planning, intraoperative guidance, education 


\section{Introduction}

Advanced medical imaging has become an essential component of preoperative planning in plastic surgery. In breast reconstructive surgery, the introduction of computed tomographic angiography (CTA) has enabled surgeons to improve clinical outcomes (1) through accurate and reliable prospective selection of the donor site, flap, perforators, and the optimal mode of dissection $(2,3)$. Recent development of three-dimensional (3D) and 4D CTA techniques have enhanced spatial appreciation of the perforator vessels, their vascular territory, and dynamic flow characteristics preoperatively $(4,5)$. However, current imaging modalities are limited by being displayed on a 2D surface, such as a computer screen. In contrast, a 3D-printed haptic biomodel allows both the surgeon and the patient to develop a superior understanding of the anatomy and the procedure with the goal of improved operative planning through the ability to interact directly with a model of the patient-specific anatomy. Historically, the technically challenging nature of 3D software and the high prices of early 3D printers usually meant that clinicians keen to exploit these advantages had to outsource 3D printing and the cost of outsourcing often precluded it from being implemented widely. In this review, we analyze how recent advancements have enabled 3D printing to transition from the research and development laboratory to the clinical 'bedside' potentially making it a ubiquitous application in plastic surgery.

\section{D Printing}

3D printing, also known as rapid prototyping or additive manufacturing, describes a process by which a product derived from a computer-aided design (CAD) is built in a layer-by-layer fashion (Figure 1) (Video S1 in Supplementary Material) (6-8). In contrast to the conventional manufacturing processes like injection molding, 3D printing has introduced an era of design freedom and enabled rapid production of customized objects with complex geometries $(9-11)$. One of the major advantages of $3 \mathrm{D}$ printing is the capacity to directly translate a concept into an end product in a convenient, cost-efficient manner. It eliminates the typical intermediary stages involved in a product development, such as development, production, assembly lines, delivery, and warehousing of parts (12), and the subsequent savings made from using fewer materials and labor lead to an overall reduction in the cost of production (13).

$3 \mathrm{D}$ printing has been utilized in industrial design since the 1980s; however, it has only become adapted for medical application in the last decade (14). Imaging data from routine computed tomography (CT) or magnetic resonance imaging (MRI) can be converted into a CAD file using a variety of 3D software programs, such as Osirix (Pixmeo, Geneva, Switzerland) or 3D Slicer (Surgical Planning Laboratory, Boston, MA, USA) (Figure 1). These files are processed into data slices suitable for printing by proprietary softwares from the $3 \mathrm{D}$ printer manufacturers. While a range of 3D printing techniques have been developed for industrial use; stereolithography (SLA), multijet modeling (MJM), selective laser sintering (SLS), binder jetting, and fused deposition modeling (FDM) are the main approaches that have

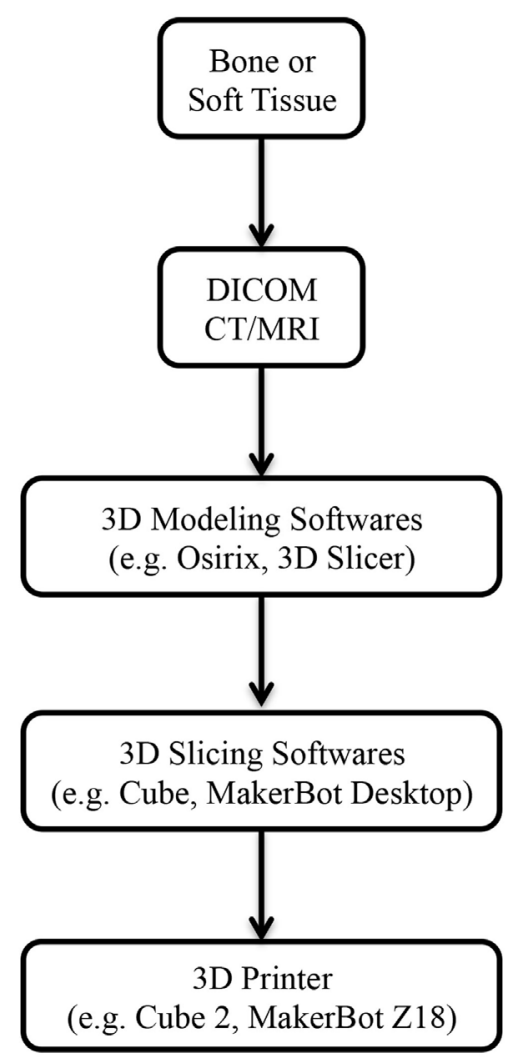

FIGURE 1 | Steps involved from imaging to 3D-printed models. Abbreviations: DICOM, digital imaging and communications in medicine; CT, computed tomography; MRI, magnetic resonance imaging.

been explored in the clinical setting (Table 1). We will explore each of these to evaluate their current and potential applications in clinical practice for both bony reconstruction and soft tissue reconstruction.

\section{Types of 3D Printing}

\section{Stereolithography}

Stereolithography is the earliest 3D printing technology described for fabricating biomodels, where a layer of liquid photopolymer or epoxy resin in a vat is cured by a low-power ultraviolet (UV) laser (15). Excess raw materials and the supporting structures must be manually removed from the final product and cured in a UV chamber (16-18). Currently, SLA is considered the gold standard in $3 \mathrm{D}$ biomodel production and can yield resolutions of up to $0.025 \mathrm{~mm}$. Moreover, its efficiency increases when constructing larger objects and is able to faithfully reproduce internal structural details (19). However, the need for manual post-build handling makes it labor-intensive and it still takes more than a day to produce a large model. Furthermore, in comparison to other 3D printing techniques, it is considered more expensive due to the high cost of the raw materials and for the printer upkeep $(20,21)$. Recently, a novel modification to SLA has been developed called continuous liquid interface production (CLIP). This simplifies traditional SLA and increases the production speed by harnessing oxygen 
TABLE 1 | A summary of the most commonly used 3D printing techniques in medical application.

\begin{tabular}{|c|c|c|}
\hline $\begin{array}{l}\text { 3D printing } \\
\text { techniques }\end{array}$ & Pros & Cons \\
\hline SLA & $\begin{array}{l}\text { Current gold standard } \\
\text { High resolution } \\
\text { Increased efficiency with } \\
\text { increase in print size } \\
\text { Detailed fabrication of } \\
\text { internal structures }\end{array}$ & $\begin{array}{l}>1 \text { day of printing time required } \\
\text { Require extensive post-production } \\
\text { manual handling } \\
\text { High cost related to the materials, } \\
\text { the printer, and the maintenance }\end{array}$ \\
\hline MJM & $\begin{array}{l}\text { High resolution } \\
\text { Minimal post-production } \\
\text { manual handling } \\
\text { Multiple materials }\end{array}$ & $\begin{array}{l}\text { High cost related to the material } \\
\text { and printer } \\
\text { Poorer surface finishing than SLA }\end{array}$ \\
\hline SLS & $\begin{array}{l}\text { Not require support } \\
\text { structures } \\
\text { Smooth surface finishing } \\
\text { Print delicate structures } \\
\text { Print in metal }\end{array}$ & $\begin{array}{l}\text { Require post-production manual } \\
\text { handling } \\
\text { High cost related to the materials, } \\
\text { the printer, and the maintenance } \\
\text { Require expert handling of the } \\
\text { printer }\end{array}$ \\
\hline BJT & $\begin{array}{l}\text { Not require support } \\
\text { structures } \\
\text { Multiple colors } \\
\text { Multiple materials }\end{array}$ & $\begin{array}{l}\text { Brittle } \\
\text { Require extensive post-production } \\
\text { manual handling } \\
\text { Poor surface finish }\end{array}$ \\
\hline FDM & $\begin{array}{l}\text { Low cost } \\
\text { Minimal maintenance } \\
\text { High availability of printers }\end{array}$ & $\begin{array}{l}\text { Require post-production manual } \\
\text { removal of support structures } \\
\text { Poor surface finish } \\
\text { Mono-color and mono-material } \\
\text { with the current technology }\end{array}$ \\
\hline
\end{tabular}

SLA, stereolithography; MJM, multijet modeling; SLS, selective laser sintering; BJT, binder jet technique; FDM, fused deposition modeling.

inhibition of UV-curable resin photopolymerization (22). This emerging modality has yet to be evaluated in plastic and reconstructive surgery but holds promise due to its combination of speed, structural integrity, and ability to fabricate complex structures.

\section{MultiJet Modeling}

Multijet modeling printing, also known as MultiJet Printing (3D Systems, Rock Hill, SC, USA) or Poly Jet Technology (Stratasys, Edina, MN, USA), is akin to SLA, but the liquid photopolymer is immediately cured by the UV light preventing the time-consuming post-processing in the UV chamber and the prototypes are built with gel-like support materials that are readily dissolvable in water (23). MJM can manufacture models with high resolution $(16 \mu)$ that is comparable to or better than SLA, with an added benefit of the capacity to print in multiple materials for the desired degree of tensile strength and durability. Furthermore, a MJM printer is easier to maintain than a SLA set-up. However, the high price of these printers makes MJM more suitable for large-scale productions than for office-based/bedside desktop application.

\section{Selective Laser Sintering}

Selective laser sintering describes a process where powdered forms of thermoplastic, metal, glass, or ceramic material are sintered by high-power laser beams in a layer-by-layer fashion $(24,25)$. Similar to SLA, the unsintered powders must be brushed away from the final product; however, they provide support and eliminate the need for support structures. As a result, SLS yields models with smoother surface finish and facilitates the production of delicate structures with high accuracy. Furthermore, the unsintered powders can be reused leading to a reduction in cost compared to SLA $(20,26)$. However, SLS remains significantly more expensive than binder jet technique (BJT) (below) and FDM, due mainly to the cost of the printer. In addition, SLS printers can be potentially hazardous due to the presence of lasers, pistons, and gas chambers that can reach extremely high temperatures and hence, requires expert handling. These features have discouraged it from being widely implemented in non-industrial settings.

\section{Binder Jet Technique}

Binder jet technique, or powder bed technique, is the first $3 \mathrm{D}$ printing approach that reduced the cost of $3 \mathrm{D}$ printers, thereby enabling a widespread consumerization of 3D printing (27). Similar to the SLS process, printer heads eject a binder material along with colored dye onto a layer of powder, fusing them layer-by-layer into a plaster model (28). Unfused powders provide adequate support for the "overhanging" designs and hence, simultaneous deposition of support structures is rarely required. Moreover, binder jet $3 \mathrm{D}$ printers can print in multiple colors and materials, and have multiple printer heads for faster printing. One of the major drawbacks of binder jetting is that the final product usually lacks strength and has a poorer surface finish than SLA or SLS. Hence, all models require post-production strengthening with materials such as melted wax, cyanoacrylate glue, or epoxy.

\section{Fused Deposition Modeling}

Fused deposition modeling is the most commonly used consumer $3 \mathrm{D}$ printing technology available currently and is also the most affordable $(21,29,30)$. A melted filament of thermoplastic material is extruded from a nozzle moving in the $x-y$ plane and solidifies upon deposition on a build plate (31). After each layer, the build plate is lowered by $0.1 \mathrm{~mm}$ and the process is repeated until the final product is produced. Acrylonitrile-butadiene-styrene (ABS) and polylactic acid (PLA) are the most frequently used raw materials in FDM printers. A notable shortcoming for the use of FDM in medical applications is that most anatomical structures have complex shapes and hence, would require support structures. Although they are easy to remove manually, the aftermath generally leaves superficial damage to the model compromising its surface finish and esthetics. Hollow internal structures or blind-ended openings are particularly difficult to clean build material from. Furthermore, most household FDM printers are currently limited to fabricating in mono-color and mono-material. However, this can be overcome by recently developed dual-extruder technology, where two filaments of different color or material can be extruded from a common printer head. It is currently found in printers, such as MakerBot Replicator 2X Experimental (MakerBot Industries, New York, NY, USA), Cube 3 (3D Systems, Rock Hill, SC, USA), and Creatr x1 (Leapfrog, Emeryville, CA, USA). Moreover, the second extruder can be configured to build support structures using MakerBot Dissolvable Filament (MakerBot Industries), made up of high impact polystyrene (HIPS) (32). When the final product is immersed in water with limonene, a widely available 
citrus-scented solvent, the support structures selectively dissolve away within 8 to $24 \mathrm{~h}$ but these dual extruder printers have not yet become established in the mainstream.

\section{D Printing in Medicine}

In the last decade or so, researchers have demonstrated a wide range of uses for $3 \mathrm{D}$ printing across numerous surgical disciplines. Clinically, 3D-printed haptic biomodels provide a tactile feedback and enable users to simulate complex anatomical movements, such as articulation at the temporomandibular joint, that are difficult to reproduce in a computer software (33). As a result, they facilitate an enhanced appreciation of the visuospatial relationship between anatomical structures for the surgeons (34). This can translate into shorter operative time, reduced exposure to general anesthesia, shorter wound exposure time and reduced intraoperative blood loss $(18,35,36)$.

\section{Preoperative Planning}

In preoperative planning, 3D-printed biomodels have been beneficial in orbital and mandibular reconstruction in maxillofacial surgery (21, 37-41); craniofacial, skull base, and cervical spine reconstruction in neurosurgery (35); prefabrication of bony fixation plates and planning excision of bony lesions in orthopedic surgery $(42,43)$; mapping complex congenital heart defects and tracheobronchial variation in cardiothoracic surgery and cardiac transplantation $(26,44-52)$ (Figure 2); endovascular repair of abdominal aortic aneurysm and aortic dissection in vascular surgery (53-55); partial nephrectomy for renal tumors in urology (56); osteoplastic flap reconstruction of frontal sinus defects in ear, nose, and throat surgery $(57,58)$; and hepatectomy and liver transplantation in general surgery (59-61).

\section{Intraoperative Guidance}

Furthermore, 3D softwares have been used to fabricate patientspecific surgical templates and intraoperative guidance devices to aid surgeons in maxillofacial surgery (62-67), neurosurgery (68), orthopedic surgery (69), hand surgery (70), and general surgery (71).

\section{Education}

3D-printed haptic biomodels can be useful for educating patients during medical consultations and training surgical trainees (29, $45,72-81)$.

\section{Customized Prosthesis}

Moreover, 3D printing has enabled rapid and convenient production of customized implants. Investigators have manufactured patient-specific mandibular implants in maxillofacial surgery (82-84), cranial vault implants for cranioplasty in neurosurgery $(85,86)$, hip implants in orthopedic surgery $(87,88)$, and a bioresorbable airway splint for complex tracheobronchomalacia in pediatric cardiothoracic surgery (89).

\section{Allied Health}

In other areas of medicine, 3D printing has revolutionized the manufacturing of hearing aids and currently $99 \%$ of all hearing aids in the world are 3D printed (90). Additionally, 3D printing

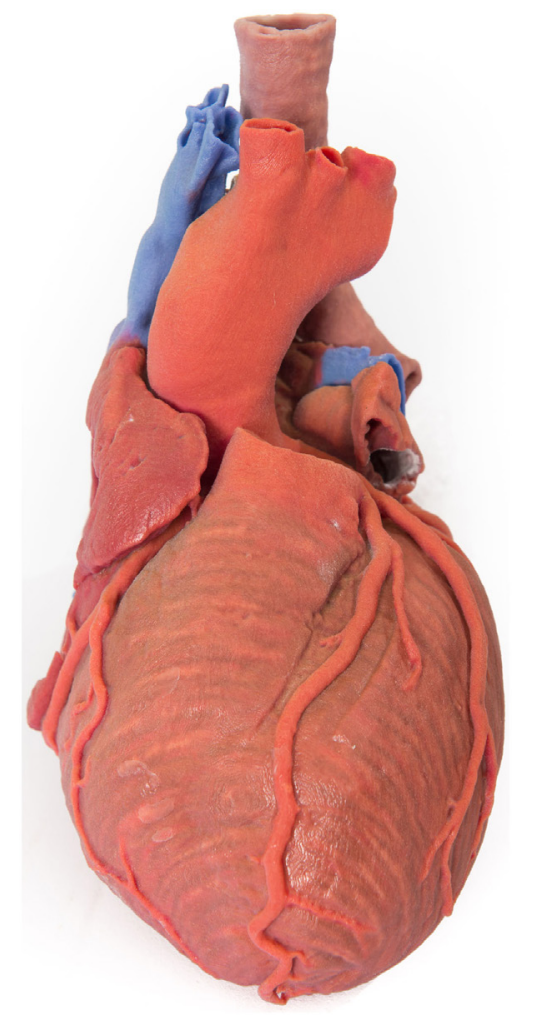

FIGURE 2 | 3D-printed haptic model of a heart and the great vessels fabricated using Projet $\mathbf{x} 60$ series 3D printers. Reproduced with permission from Centre for Human Anatomy and Education.

has helped in making complex diagnoses in forensic medicine (91); reformed anatomy education (92); helped in planning repairs of Charcot's foot in podiatry (93); permitted the fabrication of custom-made dental implants in dentistry (94-96); produced patient-specific 3D-printed medication in pharmaceutical industry $(97,98)$; and assembled custom-design tissue scaffolds in regenerative medicine $(99,100)$.

\section{D Printing at the Bedside}

Despite a vast potential scope of $3 \mathrm{D}$ printing in clinical practice and significant media interest with frequent reports of the latest innovative advancements made using this technology (101). The incorporation of $3 \mathrm{D}$ printing as a clinical bedside application has not been widespread (102). One potential barrier is the perception amongst clinicians that $3 \mathrm{D}$ printing is technically sophisticated and is reserved for planning intricate operations and devising highly specialized implants (102). As a result, 3D printing is often outsourced to an external company, which compounds the cost and time. This demonstrates a lack of awareness of the increasing accessibility of the $3 \mathrm{D}$ softwares and the declining cost of the $3 \mathrm{D}$ printers (102).

\section{D Reconstruction Software}

In order to fabricate a 3D biomodel, two types of software are required; firstly, a " $3 \mathrm{D}$ modeling" software that translates the 
DICOM (digital imaging and communications in medicine) files from CT/MRI scans into a CAD file, and secondly, a "3D slicing" software that divides the CAD file into thin data slices suitable for 3D printing (103).

\section{D Modeling Software}

A range of 3D modeling softwares is available (Table 2); however, early ones, such as Mimics (Materialise NV, Leuven, Belgium), would incur a high cost for the initial purchase and for the ongoing software updates. Driven by the consumerization of $3 \mathrm{D}$ printing and an increasing number of both professional and community software developers, free open-source softwares, such as Osirix (104) and 3D Slicer (105-107), have become widely utilized. Our group prefers using them due to the latter's expansive developer community base, called the Slicer Community, a plethora of plug-in functions, and a user interface that is intuitive to an individual with no engineering background $(108,109)$. An ideal 3D modeling software should be free; capable of highlighting the region of interest and eliminate undesired areas using the threshold and the segmentation function, respectively; export the $3 \mathrm{D}$ model as a CAD file in a universally accepted 3D file format, such as STL (standard tessellation language); and possess an easy-to-use interface. Encouragingly, there are numerous 3D modeling softwares available in the market currently that fit all of the criteria (Table 2).

\section{D Slicing Software}

3D slicing softwares digitally "slice" a CAD file into layers suitable for $3 \mathrm{D}$ printing. However, they are also useful for altering the orientation of the CAD file relative to the printer build plate to give an optimal direction, which minimizes the requirement for the support structures and, in turn, reduces the amount of material used and therefore also reduces the printing time. This process can be readily performed using proprietary softwares that accompany the $3 \mathrm{D}$ printers at no extra cost and usually possess a simple graphic user interface, such as Cube software (3D Systems) and MakerBot Desktop (MakerBot Industries).

\section{D Printers}

The cost of early 3D printers, consisting of mostly the SLA type described above, precluded widespread adoption of $3 \mathrm{D}$ printing in the initial years; however, the expiration of key patents surrounding SLA and FDM in the last decade has fueled a surge in the number of commercial developers leading to an increase in the availability and a significant reduction of the cost (Table 3 ). Several affordable SLA 3D printers have entered the market since then, such as Form 1+ (Formlabs, Somerville, MA, USA) and ProJet 1200 (3D Systems). However, they are capable of building only small designs (i.e., $12.5 \mathrm{~cm} \times 12.5 \mathrm{~cm} \times 16.5 \mathrm{~cm}$ ) and hence, remain unsuitable for many applications. Similarly, current MJM and SLS 3D printers are generally bulky and expensive, and require specialized skills for safe handling of the hardware and its maintenance. Binder jet $3 \mathrm{D}$ printers are gradually being avoided due to the brittle quality of the end-products and the large size of the printer. Currently, FDM 3D printers are the preferred option as a desktop application in medicine for their affordability and practicality. The accuracy and the quality of FDM products are comparable to SLA, SLS, and binder jet (110-112). Furthermore, FDM incurs the least cost in maintenance from ongoing print materials (Table 4).

\section{D Printing in Plastic and Reconstructive Surgery}

In plastic and reconstructive surgery, 3D-printed haptic biomodels can potentially play a significant role in preoperative planning, intraoperative guidance, training and teaching, and fashioning patient-specific prosthesis (Table 5).

\section{Preoperative Planning: Soft Tissue Mapping}

Perforator flap surgery is routinely performed in the reconstruction of large soft tissue defects after trauma or an oncologic resection. Preoperative planning with CTA has revolutionized the field by enabling the reconstructive surgeon to identify an ideal donor site, flap, and perforator for a free flap transfer $(3,123)$, facilitating a greater flap success rate and an overall improvement in the

TABLE 2 | A summary of 3D modeling softwares that can convert a DICOM data from a standard CT/MRI scans into a CAD file.

\begin{tabular}{|c|c|c|c|c|c|c|}
\hline Name & Company & Free & $\begin{array}{c}\text { Threshold/ } \\
\text { segmentation }\end{array}$ & Export STL & $\begin{array}{l}\text { Easy user } \\
\text { interface }\end{array}$ & OS platform \\
\hline 3D Slicer & Surgical Planning Laboratory & Y & Y & Y & Y & W, M \\
\hline MITK & German Cancer Research Centre & Y & Y & Y & Y & W, M \\
\hline Osirix & Pixmeo & Y & Y & Y & Y & $\mathrm{M}$ \\
\hline MIPAV & $\mathrm{NIH} \mathrm{CIT}$ & Y & Y & Y & $\mathrm{N}$ & W, M \\
\hline MeVisLab & MeVis Medical Solutions AG & Y & Y & Y & $\mathrm{N}$ & W, M \\
\hline InVesalius & $\mathrm{CTI}$ & Y & Y & Y & $\mathrm{N}$ & W, M \\
\hline Mimics & Materialise NV & $\mathrm{N}$ & Y & Y & Y & W, M \\
\hline Avizo/Amira & FEI Visualization Science Group & $\mathrm{N}$ & Y & Y & Y & W, M \\
\hline 3D Doctor & Able Software & $\mathrm{N}$ & Y & Y & Y & W \\
\hline Dolphin Imaging 3D & Dolphin Imaging and Management & $\mathrm{N}$ & Y & Y & Y & W \\
\hline Analyze & AnalyzeDirect & $\mathrm{N}$ & Y & Y & $\mathrm{N}$ & W, M \\
\hline GuideMia & GuideMia & $\mathrm{N}$ & Y & Y & $\mathrm{N}$ & $\mathrm{W}, \mathrm{M}$ \\
\hline OnDemand3D & CyberMed & $\mathrm{N}$ & $\mathrm{N}$ & Y & $\mathrm{N}$ & $\mathrm{W}, \mathrm{M}$ \\
\hline VoXim & IVS Technology & $\mathrm{N}$ & Y & Y & $\mathrm{N}$ & W \\
\hline ScanIP & Simpleware & $\mathrm{N}$ & Y & Y & $\mathrm{N}$ & W \\
\hline
\end{tabular}

STL, standard tessellation language; OS, operating system; Y, yes; N, no; W, Windows OS; M, Mac OS. 
TABLE 3 | A summary of commercially available 3D printers from ten leading 3D printing companies in the world.

\begin{tabular}{|c|c|c|c|c|c|c|c|}
\hline Type & Name & Company & Cost (USD) & Print area $(\mathrm{cm})$ & $\begin{array}{l}\text { Print } \\
\text { resolution }(\mathrm{nm})\end{array}$ & Printer size (cm) & $\begin{array}{c}\text { Printer } \\
\text { weight (kg) }\end{array}$ \\
\hline SLA & Form 1+ & Formlabs & 3,999 & $12.5 \times 12.5 \times 16.5$ & 25 & $30.0 \times 28.0 \times 45.0$ & 8 \\
\hline SLA & ProJet 1200 & 3D Systems & 4,900 & $4.3 \times 2.7 \times 15.0$ & 30.5 & $22.9 \times 22.9 \times 35.6$ & 9 \\
\hline SLA & ProJet 6000 & 3D Systems & 200,000 & $25.0 \times 25.0 \times 25.0$ & 50 & $78.7 \times 73.7 \times 183.0$ & 181 \\
\hline SLA & ProJet 7000 & 3D Systems & 300,000 & $38.0 \times 38.0 \times 25.0$ & 50 & $98.4 \times 85.4 \times 183.0$ & 272 \\
\hline SLA & ProX 950 & 3D Systems & 950,000 & $150.0 \times 75.0 \times 55.0$ & 50 & $220.0 \times 160.0 \times 226.0$ & 1,951 \\
\hline MJM & Objet 24 series & Stratasys & 19,900 & $23.4 \times 19.2 \times 14.9$ & 28 & $82.5 \times 62.0 \times 59.0$ & 93 \\
\hline MJM & Objet 30 series & Stratasys & 40,900 & $29.4 \times 19.2 \times 14.9$ & 28 & $82.5 \times 62.0 \times 59.0$ & 93 \\
\hline MJM & ProJet 3510 series & 3D Systems & 69,500 & $29.8 \times 18.5 \times 20.3$ & 16 & $29.5 \times 47.0 \times 59.5$ & 43.4 \\
\hline MJM & Objet Eden & Stratasys & 123,000 & $49.0 \times 39.0 \times 20.0$ & 16 & $132.0 \times 99.0 \times 120.0$ & 410 \\
\hline MJM & ProJet 5000 & 3D Systems & 155,000 & $53.3 \times 38.1 \times 30.0$ & 32 & $60.3 \times 35.7 \times 57.1$ & 53.8 \\
\hline MJM & ProJet 5500X & 3D Systems & 155,000 & $53.3 \times 38.1 \times 30.0$ & 29 & $80.0 \times 48.0 \times 78.0$ & 115.7 \\
\hline MJM & Connex series & Stratasys & 164,000 & $49.0 \times 39.0 \times 20.0$ & 16 & $140.0 \times 126.0 \times 110.0$ & 430 \\
\hline MJM & Objet Connex series & Stratasys & 164,000 & $49.0 \times 39.0 \times 20.0$ & 16 & $142.0 \times 112.0 \times 113.0$ & 500 \\
\hline MJM & Objet 1000 & Stratasys & 614,000 & $100.0 \times 80.0 \times 50.0$ & 16 & $280.0 \times 180.0 \times 180.0$ & 1,950 \\
\hline SLS & sPro series & 3D Systems & 300,000 & $55.0 \times 55.0 \times 46.0$ & 80 & $203.0 \times 160.0 \times 216.0$ & 2,700 \\
\hline SLS & ProX series & 3D Systems & 500,000 & $38.1 \times 33.0 \times 45.7$ & 100 & $174.4 \times 122.6 \times 229.5$ & 1,360 \\
\hline BJT & ProJet 160 & 3D Systems & 40,000 & $23.6 \times 18.5 \times 12.7$ & 100 & $74.0 \times 79.0 \times 140.0$ & 165 \\
\hline BJT & ProJet 260C & 3D Systems & 40,000 & $23.6 \times 18.5 \times 12.7$ & 100 & $74.0 \times 79.0 \times 140.0$ & 165 \\
\hline BJT & ProJet 360 & 3D Systems & 40,000 & $20.3 \times 25.4 \times 20.3$ & 100 & $122.0 \times 79.0 \times 140.0$ & 179 \\
\hline BJT & ProJet 460 Plus & 3D Systems & 40,000 & $20.3 \times 25.4 \times 20.3$ & 100 & $122.0 \times 79.0 \times 140.0$ & 193 \\
\hline BJT & ProJet 4500 & 3D Systems & 40,000 & $20.3 \times 25.4 \times 20.3$ & 100 & $162.0 \times 80.0 \times 152.0$ & 272 \\
\hline BJT & ProJet 660 Pro & 3D Systems & 40,000 & $25.4 \times 38.1 \times 20.3$ & 100 & $188.0 \times 74.0 \times 145.0$ & 340 \\
\hline BJT & ProJet 860 Plus & 3D Systems & 40,000 & $50.8 \times 38.1 \times 22.9$ & 100 & $119.0 \times 116.0 \times 162.0$ & 363 \\
\hline FDM & Huxley Duo & RepRapPro & 453 & $13.8 \times 14.0 \times 9.5$ & 12.5 & $26.0 \times 28.0 \times 28.0$ & 4.5 \\
\hline FDM & Mendel & RepRapPro & 586 & $21.0 \times 19.0 \times 14.0$ & 12.5 & $50.0 \times 46.0 \times 41.0$ & 8 \\
\hline FDM & Ormerod 2 & RepRapPro & 702 & $20.0 \times 20.0 \times 20.0$ & 12.5 & $50.0 \times 46.0 \times 41.0$ & 6 \\
\hline FDM & Tricolor Mendel & RepRapPro & 863 & $21.0 \times 19.0 \times 14.0$ & 12.5 & $50.0 \times 46.0 \times 41.0$ & 8 \\
\hline FDM & Cube 3 & 3D Systems & 999 & $15.3 \times 15.3 \times 15.3$ & 70 & $33.5 \times 34.3 \times 24.1$ & 7.7 \\
\hline FDM & Buccaneer & Pirate 3D & 999 & $14.5 \times 12.5 \times 15.5$ & 85 & $25.8 \times 25.8 \times 44.0$ & 8 \\
\hline FDM & Original + & Ultimaker & 1,238 & $21.0 \times 21.0 \times 20.5$ & 20 & $35.7 \times 34.2 \times 38.8$ & $\mathrm{~N} / \mathrm{A}$ \\
\hline FDM & Replicator mini & MakerBot & 1,375 & $10.0 \times 10.0 \times 12.5$ & 200 & $29.5 \times 31.0 \times 38.1$ & 8 \\
\hline FDM & Creatr & Leapfrog & 1,706 & $20.0 \times 27.0 \times 20.0$ & 50 & $60.0 \times 50.0 \times 50.0$ & 32 \\
\hline FDM & Replicator 2 & MakerBot & 1,999 & $28.5 \times 15.3 \times 15.5$ & 100 & $49.0 \times 42.0 \times 38.0$ & 11.5 \\
\hline FDM & LulzBot TAZ 4 & Aleph Objects & 2,195 & $29.8 \times 27.5 \times 25.0$ & 75 & $668.0 \times 52.0 \times 51.5$ & 11 \\
\hline FDM & AW3D HDL & Airwolf 3D & 2,295 & $30.0 \times 20.0 \times 28.0$ & 100 & $61.0 \times 44.5 \times 46.0$ & 17 \\
\hline FDM & Creatr HS & Leapfrog & 2,373 & $29.0 \times 24.0 \times 18.0$ & 50 & $60.0 \times 60.0 \times 50.0$ & 40 \\
\hline FDM & Replicator 2x & MakerBot & 2,499 & $24.6 \times 15.2 \times 15.5$ & 100 & $49.0 \times 42.0 \times 53.1$ & 12.6 \\
\hline FDM & Ultimaker 2 & Ultimaker & 2,500 & $23.0 \times 22.5 \times 20.5$ & 20 & $35.7 \times 34.2 \times 38.8$ & N/A \\
\hline FDM & Replicator 5th gen & MakerBot & 2,899 & $25.2 .19 .9 \times 15.0$ & 100 & $52.8 \times 44.1 \times 41.0$ & 16 \\
\hline FDM & AW3D HD & Airwolf 3D & 2,995 & $30.0 \times 20.0 \times 30.0$ & 60 & $61.0 \times 44.5 \times 46.0$ & 17 \\
\hline FDM & Cube Pro & 3D Systems & 3,129 & $20.0 \times 23 \times 27.0$ & 100 & $57.8 \times 59.1 \times 57.8$ & 44 \\
\hline FDM & AW3D HDX & Airwolf 3D & 3,495 & $30.0 \times 20.0 \times 30.0$ & 60 & $61.0 \times 44.5 \times 46.0$ & 17 \\
\hline FDM & AW3D HD2X & Airwolf 3D & 3,995 & $27.9 \times 20.3 \times 30.5$ & 60 & $61.0 \times 45.7 \times 45.7$ & 18 \\
\hline FDM & Creatr $\mathrm{xl}$ & Leapfrog & 4,988 & $20.0 \times 27.0 \times 60.0$ & 50 & $75.0 \times 65.0 \times 126.0$ & 37 \\
\hline FDM & Replicator Z18 & MakerBot & 6,499 & $30.5 \times 30.5 \times 45.7$ & 100 & $49.3 \times 56.5 \times 85.4$ & 41 \\
\hline FDM & Xeed & Leapfrog & 8,705 & $35.0 \times 27.0 \times 60.0$ & 50 & $101.0 \times 66.0 \times 100.0$ & 115 \\
\hline FDM & Mojo & Stratasys & 9,900 & $12.7 \times 12.7 \times 12.7$ & 178 & $63.0 \times 45.0 \times 53.0$ & 27 \\
\hline FDM & uPrint & Stratasys & 13,900 & $20.3 \times 15.2 \times 15.2$ & 254 & $63.5 \times 66.0 \times 94.0$ & 94 \\
\hline FDM & $\begin{array}{l}\text { Objet Dimension } \\
\text { series }\end{array}$ & Stratasys & 40,900 & $25.4 \times 25.4 \times 30.5$ & 178 & $83.8 \times 73.7 \times 114.3$ & 148 \\
\hline FDM & Fortus series & Stratasys & 184,000 & $91.4 \times 61.0 \times 91.4$ & 127 & $277.2 \times 168.3 \times 202.7$ & 2,869 \\
\hline
\end{tabular}

Where a 3D printer series is characterized, the lowest cost, largest print area, lowest print resolution, largest printer size, and greater printer weight are selected for comparison. SLA, stereolithography; MJM, multijet modeling; SLS, selective laser sintering; BJT, binder jet technique; FDM, fused deposition modeling; cm, centimeter; kg, kilograms; nm, nanometers; N/A, not available.

clinical outcomes $(1,2,124)$. In addition to CTA, 3D biomodels can provide an additional layer of clinical information through visual and tactile examination.

In a recent report, our research group described a technique of fashioning a "reverse" model representing a soft tissue ankle defect that was utilized for planning a perforator flap-based reconstruction (Figure 3) (109). Routine CTA of the lower limbs (i.e., recipient site) and the forearms (i.e., donor site) were conducted and the DICOM data were converted into a CAD file using Osirix. The 3D image of the normal contralateral ankle was mirrored, superimposed over the image of the pathological side, and after digital subtraction using Magics software (Materialise 
TABLE 4 | A summary of average raw material cost of each 3D printing technique.

\begin{tabular}{lc}
\hline Type of 3D printing & Average cost of print material (USD) \\
\hline SLA & 200 per $\mathrm{L}$ \\
MJM & 300 per $\mathrm{kg}$ \\
SLS & 500 per $\mathrm{kg}$ \\
BJT & 100 per $\mathrm{kg}$ \\
FDM & 50 per $\mathrm{kg}$
\end{tabular}

SLA, stereolithography; MJM, multijet modeling; SLS, selective laser sintering; BJT, binder jet technique; FDM, fused deposition modeling; L, liter.

TABLE 5 | A summary of published application of 3D printing in Plastic and Reconstructive Surgery.

\begin{tabular}{|c|c|c|c|}
\hline \multicolumn{2}{|l|}{ Application } & $\begin{array}{l}\text { Example } \\
\text { Breast reconstruction }\end{array}$ & $\begin{array}{c}\text { Reference } \\
(108)\end{array}$ \\
\hline $\begin{array}{l}\text { Preoperative } \\
\text { planning }\end{array}$ & $\begin{array}{l}\text { Soft tissue } \\
\text { mapping }\end{array}$ & $\begin{array}{l}\text { Breast reconstruction } \\
\text { Ear reconstruction } \\
\text { Nasal reconstruction } \\
\text { Mandibular soft tissue tumor resection } \\
\text { "Reverse" model of ankle defect } \\
\text { Sacral defect }\end{array}$ & $\begin{array}{c}(108) \\
(113,114) \\
(115) \\
(116) \\
(109) \\
(117)\end{array}$ \\
\hline & $\begin{array}{l}\text { Vascular } \\
\text { mapping } \\
\text { Bony } \\
\text { mapping } \\
\text { 4D printing }\end{array}$ & $\begin{array}{l}\text { Internal mammary artery perforators } \\
\text { DIEA perforators } \\
\text { Basal thumb osteoarthritis }\end{array}$ & $\begin{array}{l}(118) \\
(7) \\
(7)\end{array}$ \\
\hline \multirow{2}{*}{\multicolumn{2}{|c|}{$\begin{array}{l}\text { Intraoperative guidance } \\
\text { Surgical training }\end{array}$}} & Bone reduction clamp & (70) \\
\hline & & $\mathrm{N} / \mathrm{A}$ & \\
\hline \multicolumn{2}{|c|}{ Patient education } & $\mathrm{N} / \mathrm{A}$ & \\
\hline \multicolumn{2}{|c|}{$\begin{array}{l}\text { Patient-specific } \\
\text { prosthesis }\end{array}$} & $\begin{array}{l}\text { Craniofacial implant } \\
\text { "Ear and nose library" }\end{array}$ & $\begin{array}{c}(120) \\
(121,122)\end{array}$ \\
\hline
\end{tabular}

DIEA, deep inferior epigastric artery; 4D, four dimensional; N/A, not available.

NV), a "reverse" model representing the wound defect is created (Figure 4). This mirroring function can also be performed in free open-source softwares, such as Osirix and 3D Slicer. This helped the surgeon preoperatively appreciate the length, width, and depth of the free flap that needed to be harvested in order to adequately cover the defect. Both the pathological ankle and the "reverse" model were fabricated in PLA filaments using a Cube 2 printer (3D Systems) (Figures 5 and 6) (Table S1 in Supplementary Material).

We also recently demonstrated the utility of a 3D-printed biomodel for planning perforator flap reconstruction of a sacral wound defect post-oncologic resection (117). Likewise, we used Osirix to translate the preoperative sacral CTA data into a CAD file. Due to the maximal build dimensions of the Cube 2 printer (i.e., $16 \mathrm{~cm} \times 16 \mathrm{~cm} \times 16 \mathrm{~cm}$ ), the 3D image of the sacral defect was scaled down using the Cube software. The haptic model still accurately represented the shape and depth of the defect and its relationship with the surrounding anatomical structures.

$3 \mathrm{D}$ printing can potentially be a valuable tool in the assessment of soft tissue volume. Volumetric analysis is an essential component of breast reconstructive surgery and currently surgeons rely on 2D photography or 3D scanning technology, such as VECTRA (Canfield Imaging Systems, Fairfield, NJ, USA) (125), and subjective visual assessment. One of the main limitations of 3D photography like VECTRA is the inability to account for an underlying chest wall asymmetry that may

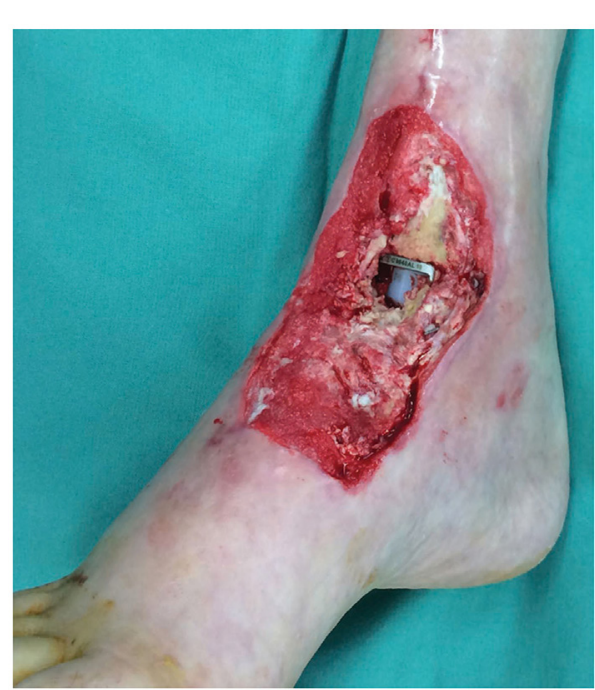

FIGURE 3 | Photograph of the soft tissue ankle defect showing the exposed metal hardware from a previous ankle reconstruction. Reproduced with permission from Microsurgery (109).

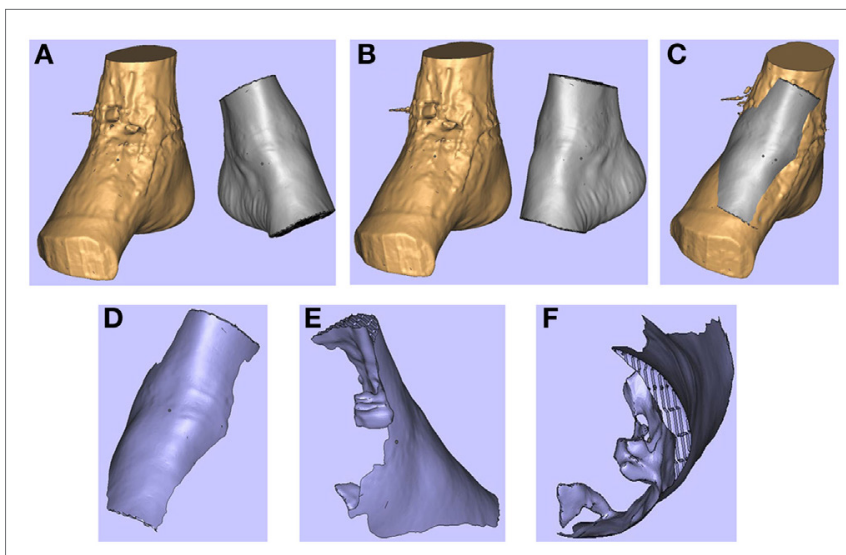

FIGURE 4 | 3D images of the right (pathological) ankle is juxtaposed to the left (normal) ankle (A). The left ankle is reflected (B) and superimposed on to the right ankle (C). These images are subtracted from each other to produce a "reverse" model of the soft tissue defect (D-F) Reproduced with permission from Microsurgery (109).

incorrectly lead to an asymmetrical appearance despite equal breast parenchymal volumes. Moreover, the accuracy of each scan is reliant on the patients standing with their back flat against a wall, which may not be feasible in certain conditions, such as kyphosis or scoliosis. Recently, we reported the use of a $3 \mathrm{D}$-printed model of a patient with post-mastectomy breast asymmetry for preoperative planning (Figure 7) (108). Despite being scaled down to fit the build size of the printer, having an accurate physical replica helped surgeons appreciate the difference in the breast shape and volume. Furthermore, using the segmentation function in Osirix we were able to quantify the breast parenchymal volume difference. 


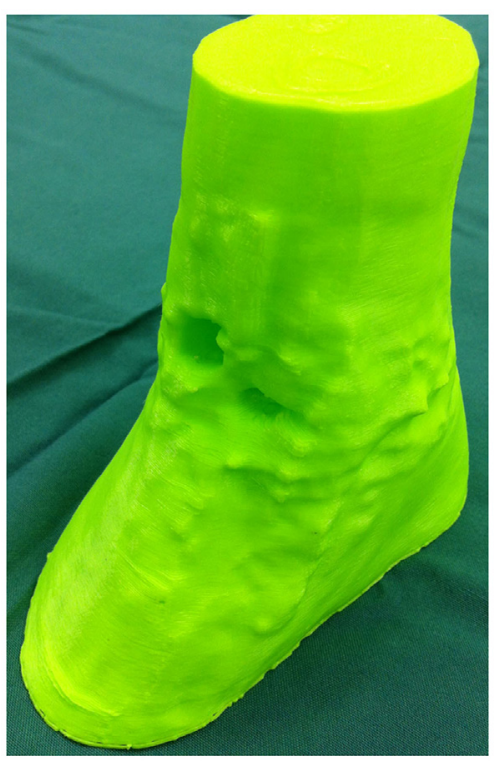

FIGURE 5 | 3D-printed haptic model of the soft tissue ankle defect. Reproduced with permission from Microsurgery (109).

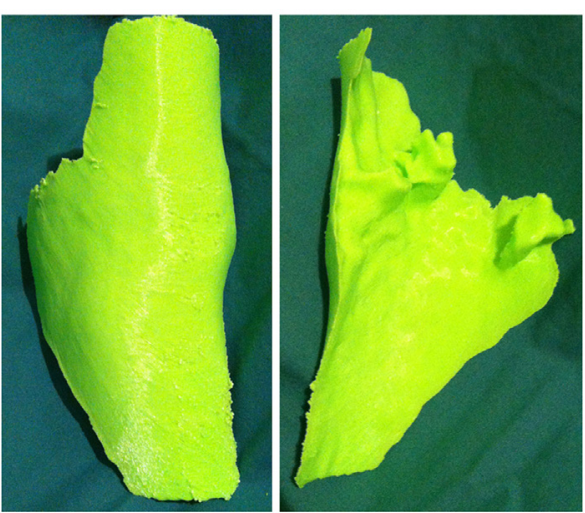

FIGURE 6 | 3D-printed haptic model of the "reverse" image representing the wound defect. Reproduced with permission from Microsurgery (109).

\section{Preoperative Planning: Vascular Mapping}

Understanding the vascular anatomy of perforators and their relationship with the regional anatomical structures is critical in perforator flap surgery and to this effect, CTA is currently the gold standard preoperative investigation $(1,2,123,126)$. Recently, Gillis and Morris reported a cadaveric study where a model of internal mammary artery perforators and the neighboring ribs was fabricated using a binder jet 3D printer (ProJet x60 series, 3D Systems) (118). The authors demonstrated the benefits of physically interacting with the model and the ability to visualize it in multiple planes to aid dissection and identification of the dominant perforator. However, they also noted a significant cost associated with outsourcing the 3D printing (USD 400-1,200) and the print material was too delicate for small-size blood vessels that required post-production strengthening with wax coating.

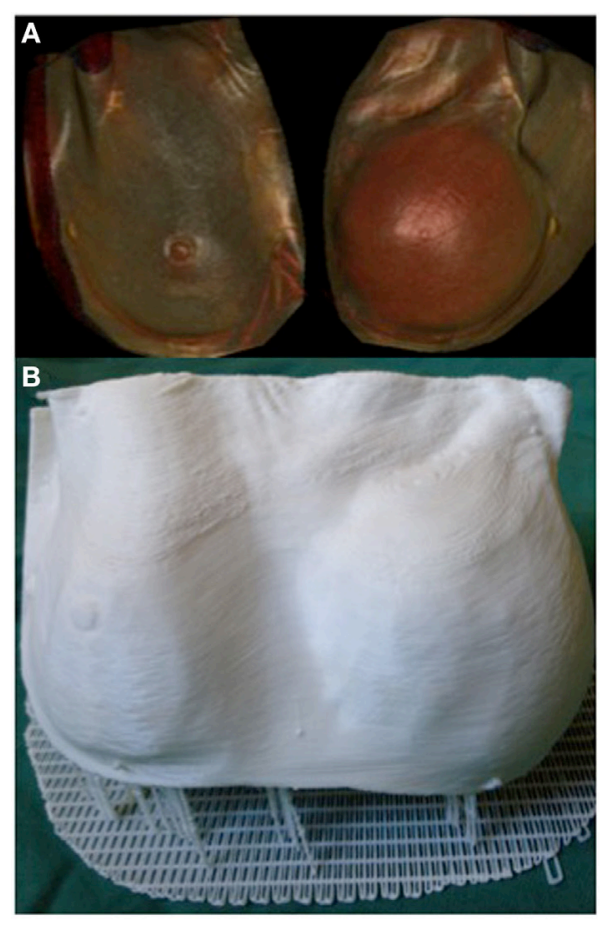

FIGURE 7 | 3D reconstructed CT images of a patient with breast asymmetry post-mastectomy $(\mathrm{A})$ and the $3 \mathrm{D}$ printed breast model of the same patient (B). Reproduced with permission from Breast Cancer Research and Treatment (108).

Likewise, our group 3D printed the perforator anatomy for planning a deep inferior epigastric artery perforator (DIEP) flap breast reconstruction. From the preoperative CTA, we created a CAD file of the deep inferior epigastric artery (DIEA) with the surrounding bony landmarks using 3D slicer and the Cube 2 printer. Despite having to scale down the model to fit the printer dimensions, surgeons could intuitively discern the arterial anatomy from the replica. Interestingly, the current technique impeded the perforators of DIEA to be 3D printed. Considering that the DICOM data of the CTA and the Cube 2 printer have a resolution of 0.625 and $0.200 \mathrm{~mm}$, respectively, and the mean diameter of a DIEA perforator ranges between 1 and $1.4 \mathrm{~mm}$ (127), this may be most likely explained as a limitation of the 3D modeling software, $3 \mathrm{D}$ Slicer. This may be prevented in the future by installing free add-on software functions, such as Vascular Modeling Toolkit (VMTK, Orobix, Bergamo, Italy) in 3D Slicer, that are designed to specifically segment vascular structures. Currently, these are still early in the development phase and are difficult to manipulate without significant computer engineering proficiencies. As the field advances, we would naturally expect the user interface of these softwares to become easier to use.

\section{Preoperative Planning: Bony Mapping}

$3 \mathrm{D}$ printing bony pathology in the forearm, wrist, and hand is another suitable utility of this technology in plastic and reconstructive surgery. CT scans have been the most commonly used imaging modality for medical 3D printing. Since they readily differentiate bones, $3 \mathrm{D}$ printing bony structures has become well established in various surgical disciplines, such as maxillofacial surgery $(20,21$, 
$33,128-130)$, neurosurgery $(35,68,86)$, and orthopedic surgery (131-135). Using Osirix and Cube 2 printer, our research group 3D printed a model of a subluxed first carpometacarpal joint. Being able to visualize the model from various angles and the tactile feedback facilitated an intuitive understanding of the anatomical relationship between the first metacarpal and the trapezium. The information was useful for planning the optimal method of reduction.

\section{A New Evolution: 4D Printing}

Recently, we described for the first time the concept of applying $3 \mathrm{D}$ printing to $4 \mathrm{D}$ CT scans, or $4 \mathrm{D}$ printing, where time is added as the fourth dimension to the standard 3D printing (119). 4D CT is a novel imaging modality developed to remove motion artifacts from organs, such as lungs, in order to enhance the image quality and facilitate precise delivery of radiotherapy $(136,137)$. In plastic surgery, investigators have utilized 4D CTA to assess the vascular territories and the dynamic flow characteristics of an individual perforator $(4,5)$. Using Osirix and Cube 2 printer, our group 3D printed the carpal and metacarpal bones of a patient in life-size at various stages of the thumb movement, such as thumb abduction (Figure 8). In contrast to the $3 \mathrm{D}$ reconstructions on a $2 \mathrm{D}$ computer screen and 3D models, 4D-printed haptic models accurately depicted the position of the carpal bones during each movement and enabled an instinctive appreciation of the spatiotemporal relationship between them. One of the major disadvantages was the reliance on the clinician reviewing the 4D CT data to select the scans most representative of the carpal bone transition during each movement for $3 \mathrm{D}$ printing. This can be overcome as $3 \mathrm{D}$ printers become faster thus allowing more models to be fabricated.

\section{Intraoperative Guidance}

The convenience of 3D printing has propelled an innovation in custom designs of surgical templates and equipments that help guide the surgeon intraoperatively. In the literature, investigators have demonstrated the utility of 3D printing a modified army/navy surgical retractor (71); patient-specific orthognathic templates to guide osteotomy (66) and mandibular fracture reduction device (138) in maxillofacial surgery; screw fixation guide system in spinal neurosurgery (139); and drill templates to aid surgical correction of multilevel cervical spine instability in orthopedic surgery (69). In plastic and reconstructive surgery, Fuller et al. illustrated how $3 \mathrm{D}$ printing can expedite the

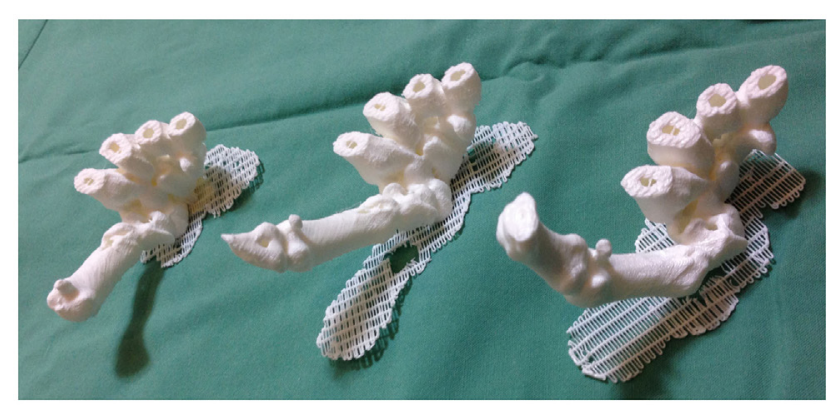

FIGURE 8 | 4D-printed haptic models of carpal and metacarpal bones demonstrating thumb abduction (from left to right). Reproduced with permission from Journal of Reconstructive Microsurgery (119). development of a custom-made bone reduction clamp design for hand fractures, in comparison to the conventional processes that can become protracted and actually be discouraging to innovation (70). The authors collaborated with an engineer to produce 3D prototype designs and converted them into CAD files using free 3D softwares, such as SketchUp (Trimble Navigation, Sunnyvale, CA, USA) and MeshLab (ISTI-CNR, Pisa, Italy), respectively. 3D printing of the FDM prototypes was outsourced, costing USD 75 and 1-3 days for the delivery to arrive. The final design was manufactured in metal using an additive manufacturing technique, called direct metal laser sintering, and was again outsourced, costing USD 1,200 and 2 days for the delivery. The authors acknowledged that the $3 \mathrm{D}$ softwares for designing prototypes are currently not intuitive for clinicians with only basic computer proficiency. Furthermore, the final cost exceeded the cost of purchasing a standard equipment. However, as $3 \mathrm{D}$ printing technology advances and the 3D printing is performed "in-house", the difference may become minimal in the future.

\section{Surgical Training}

Detailed knowledge of anatomical structures and their spatial relationships are essential assets of a plastic surgeon and objectives of a surgical training program. Through the standard medical training, a surgical aspirant can gain procedural experiences from performing dissections on human cadavers as a medical student and assisting senior surgeons in the operating theater as a resident, leading toward a gradual acquisition of competence. However, human cadavers are becoming relatively scarce from the anatomical education curricula due to high maintenance costs, cultural and social controversies, and safety issues associated with the formalin-containing embalming fluids $(92,140)$. Furthermore, the operative experience gained as an assistant to a senior surgeon is secondary to a primary operator experience. To this end, 3D-printed anatomical models can serve as an accurate, tactile visualization tool and a surgical simulation device. Moreover, 3D-printed haptic biomodels can be utilized to reproduce complex, patient-unique pathologies that facilitate the surgical trainees to preoperatively predict potential intraoperative challenges and postoperative outcomes and aid in their learning. Subsequent improvement in the surgeon's competence may lead to enhanced clinical outcomes and a reduced risk of complications. Investigators from various surgical disciplines have demonstrated the utility of $3 \mathrm{D}$ printing in training, such as neurosurgery $(72-77$, $141,142)$, cardiothoracic surgery $(54,78-80,143-145)$, urology $(81,146)$, and general surgery (29) However, one of the major limitations currently is the ability to print in materials that closely mimic the biomechanical properties and modulus of real human tissue as well as possessing realistic colors. As more materials enter the scope of 3D printing, future 3D-printed biomodels will be able to more closely reproduce true anatomy $(50,72,74,79)$.

\section{Patient Education}

3D-printed replicas can be useful to facilitate the physician-patient interaction during a consultation with the aim of improved understanding of the intended procedure, its potential outcomes and complications and thus can form an important aspect of informed consent. Traditional CT/MRI scans are often difficult to comprehend for patients from a non-medical background. In recent times, plastic surgeons have utilized 3D scanning technology, such as 
VECTRA (Canfield Imaging Systems), to accurately simulate potential outcomes from a cosmetic procedure on a computer screen (125). However, studies have consistently demonstrated that visual and tactile feedback from a 3D haptic model provides a superior understanding of anatomical details compared to $2 \mathrm{D}$ or $3 \mathrm{D}$ imaging techniques $(34,58,147)$.

\section{Patient-Specific Prosthesis}

As modern medicine ultimately progresses toward individualized treatment approaches, customizability of $3 \mathrm{D}$ printing can transform the manufacturing of patient-specific prostheses to being widely accessible and affordable. In comparison to a standard implant, a custom-made one is more likely to yield superior functional and esthetic outcomes $(148,149)$. Typical 3D printing materials can be sterilized using chemicals, such as Food and Drug Administration approved glutaraldehyde protocols (71), steam (20), and gas (150) for intraoperative handling. In the last decade, investigators have reported 3D-printed prostheses of nose $(121,151)$, ears (122, $152-155)$, eyes $(156,157)$, face $(158,159)$, and hand $(6,160)$. Furthermore, an Italian research group led by De Crescenzio and Ciocca has established an "Ear and Nose Library" where CAD files of 3D scanned ears and noses of normal university students are stocked $(121,122)$. When patients have pathology affecting both ears or the entire nose that impedes mirroring of the normal contralateral side to reconstruct the defect, the clinicians can select the most suitable CAD file from this database to fashion a prosthesis. In plastic surgery, standard breast implants are available in different volumes, but in a limited number of shapes. To this effect, 3D-printed breast implants customized to conform to the individual variations in the chest wall anatomy and the patient's desired breast shape and size may lead to a more esthetic and satisfactory outcome.

Most reports have indicated that $3 \mathrm{D}$-printed custom prostheses provide superior esthetics in comparison to the traditional waxbased handcrafted prosthetics $(152,154,155)$. Furthermore, customized implants eschew the need to intraoperatively modify and adjust associated with the standard implants, which can directly lead to improved clinical outcomes, such as a reduction in the length of surgery, reduced exposure to anesthetics, and a decreased risk of complications like infection $(161,162)$. Currently, one of the major drawbacks is that most custom implants are manufactured using expensive 3D printing techniques, such as MJM (157) and SLS $(151,160)$. In contrast, the affordable FDM 3D printers are used to fabricate negative molds for silicone or wax-based casts, which ironically increases the overall production time and cost $(121,122,152-154,156,158)$. This is mainly because at present,

\section{References}

1. Rozen WM, Anavekar NS, Ashton MW, Stella DL, Grinsell D, Bloom RJ, et al. Does the preoperative imaging of perforators with CT angiography improve operative outcomes in breast reconstruction? Microsurgery (2008) 28:516-23. doi:10.1002/micr.20526

2. Rozen WM, Ashton MW, Grinsell D, Stella DL, Phillips TJ, Taylor GI. Establishing the case for CT angiography in the preoperative imaging of abdominal wall perforators. Microsurgery (2008) 28:306-13. doi:10.1002/micr.20496

3. Rozen WM, Ashton MW, Stella DL, Phillips TJ, Grinsell D, Taylor GI. The accuracy of computed tomographic angiography for mapping the perforators of the deep inferior epigastric artery: a blinded, prospective cohort study. Plast Reconstr Surg (2008) 122:1003-9. doi:10.1097/PRS.0b013e3181845994 only ABS and PLA filaments are available for FDM and their hard material characteristic makes them unsuitable for producing soft tissue prosthetics. However, as research and development in 3D printing continues to grow exponentially and more materials become available for FDM, we expect to be able to directly create a custom-made prosthesis affordably in the near future.

\section{Future and Conclusion}

In the last decade, image-guided 3D-printed haptic biomodels have proven to represent a valuable adjunct to the conventional $2 \mathrm{D}$ imaging modalities in plastic surgery for preoperative planning, producing intraoperative guidance tools, educating surgical trainees and patients, and fashioning patient-specific implants. In the early years, the technical complexity of $3 \mathrm{D}$ softwares and the prohibitive cost of $3 \mathrm{D}$ printers restricted accessibility of 3D printing in medicine. The expiration of key $3 \mathrm{D}$ printing patents has fueled an exponential development in the field and a significant reduction in the cost. Ultimately, we envision that $3 \mathrm{D}$ printing has the potential to become ubiquitous and function as an essential clinical bedside tool for a plastic surgeon.

\section{Author Contributions}

All authors contributed to the preparation of this manuscript. The manuscript has been seen and approved by all authors. The content of this article has not been submitted or published elsewhere.

\section{Acknowledgments}

The authors would like to acknowledge Dr. Alexandra Rizzitelli at Peninsula Health for her support.

\section{Supplementary Material}

The Supplementary Material for this article can be found online at http://journal.frontiersin.org/article/10.3389/fsurg.2015.00025

TABLE S1 | A summary of the printing time and the amount of print material used to produce the 3D printed models in plastic and reconstructive surgery mentioned in the manuscript.

VIDEO S1 | A video demonstrating the binder jet 3D printing technique using a ProJet x60 series printer (3D Systems, Rock Hill, SC). After a layer of powder is deposited, a binder material mixed with colored dye is ejected on to the powder bed to fabricate a 3D haptic model in a layer-bylayer fashion. Filmed by PGM.

4. Colohan S, Wong C, Lakhiani C, Cheng A, Maia M, Arbique G, et al. The free descending branch muscle-sparing latissimus dorsi flap: vascular anatomy and clinical applications. Plast Reconstr Surg (2012) 130:776e-87e. doi:10.1097/ PRS.0b013e31826d9c5e

5. Nie JY, Lu LJ, Gong X, Li Q, Nie JJ. Delineating the vascular territory (perforasome) of a perforator in the lower extremity of the rabbit with four-dimensional computed tomographic angiography. Plast Reconstr Surg (2013) 131:565-71. doi:10.1097/PRS.0b013e31827c6e49

6. Gerstle TL, Ibrahim AM, Kim PS, Lee BT, Lin SJ. A plastic surgery application in evolution: three-dimensional printing. Plast Reconstr Surg (2014) 133:446-51. doi:10.1097/01.prs.0000436844.92623.d3

7. Chae MP, Hunter-Smith DJ, Rozen WM. Image-guided 3D-printing and haptic modeling in plastic surgery. In: Saba L, Rozen WM, Alonso-Burgos A, Ribuffo 
D, editors. Imaging in Plastic Surgery. London: CRC Taylor and Francis Press (2014). p. 819-30.

8. Goiato MC, Santos MR, Pesqueira AA, Moreno A, dos Santos DM, Haddad MF. Prototyping for surgical and prosthetic treatment. J Craniofac Surg (2011) 22:914-7. doi:10.1097/SCS.0b013e31820f7f90

9. Levy GN, Schindel R, Kruth JP. Rapid manufacturing and rapid tooling with layer manufacturing (LM) technologies, state of the art and future perspectives. CIRP Ann Manuf Technol (2003) 52:589-609. doi:10.1016/ S0007-8506(07)60206-6

10. Sealy W. Additive manufacturing as a disruptive technology: how to avoid the pitfall. Am J Eng Technol Res (2011) 11:86-93. doi:10.3727/194824 13X3608676060655

11. Hoy MB. 3D printing: making things at the library. Med Ref Serv Q (2013) 32:93-9. doi:10.1080/02763869.2013.749139

12. Srinivasan V, Bassan J.3D printing and the future of manufacturing. CSC Leading Edge Forum (2012).

13. Schubert $C$, van Langeveld $M C$, Donoso LA. Innovations in $3 D$ printing: a $3 D$ overview from optics to organs. Br J Ophthalmol (2014) 98:159-61. doi:10.1136/ bjophthalmol-2013-304446

14. Klein GT, Lu Y, Wang MY. 3D printing and neurosurgery - ready for prime time? World Neurosurg (2013) 80:233-5. doi:10.1016/j.wneu.2013.07.009

15. Hull CW. Apparatus for Production of Three-Dimensional Objects by Stereolithography. US Patent No. 4,575,330 (1986).

16. Hannen EJ. Recreating the original contour in tumor deformed mandibles for plate adapting. Int J Oral Maxillofac Surg (2006) 35:183-5. doi:10.1016/j. ijom.2005.07.012

17. Rozen WM, Ting JW, Baillieu C, Leong J. Stereolithographic modeling of the deep circumflex iliac artery and its vascular branching: a further advance in computed tomography-guided flap planning. Plast Reconstr Surg (2012) 130:380e-2e. doi:10.1097/PRS.0b013e31825903d1

18. Rozen WM, Ting JW, Leung M, Wu T, Ying D, Leong J. Advancing image-guided surgery in microvascular mandibular reconstruction: combining bony and vascular imaging with computed tomography-guided stereolithographic bone modeling. Plast Reconstr Surg (2012) 130:227e-9e. doi:10.1097/PRS.0b013e318255028e

19. Ono I, Gunji H, Suda K, Kaneko F. Method for preparing an exact-size model using helical volume scan computed tomography. Plast Reconstr Surg (1994) 93:1363-71. doi:10.1097/00006534-199406000-00005

20. Herlin C, Koppe M, Beziat JL, Gleizal A. Rapid prototyping in craniofacial surgery: using a positioning guide after zygomatic osteotomy - a case report. J Craniomaxillofac Surg (2011) 39:376-9. doi:10.1016/j.jcms.2010.07.003

21. Cohen A, Laviv A, Berman P, Nashef R, Abu-Tair J. Mandibular reconstruction using stereolithographic 3-dimensional printing modeling technology. Oral Surg Oral Med Oral Pathol Oral Radiol Endod (2009) 108:661-6. doi:10.1016/j. tripleo.2009.05.023

22. Tumbleston JR, Shirvanyants D, Ermoshkin N, Janusziewicz R, Johnson AR, Kelly D, et al. Additive manufacturing. Continuous liquid interface production of 3D objects. Science (2015) 347:1349-52. doi:10.1126/science.aaa2397

23. Almquist TA, Smalley DR. Thermal Stereolithography. US Patent No. 5,141,680 (1992).

24. Deckard C. Method and Apparatus for Producing Parts by Selective sintering. US Patent No. 4,863,538 (1989).

25. Rengier F, Mehndiratta A, von Tengg-Kobligk H, Zechmann CM, Unterhinninghofen R, Kauczor HU, et al. 3D printing based on imaging data: review of medical applications. Int J Comput Assist Radiol Surg (2010) 5:335-41. doi:10.1007/s11548-010-0476-X

26. Mottl-Link S, Hubler M, Kuhne T, Rietdorf U, Krueger JJ, Schnackenburg B, et al. Physical models aiding in complex congenital heart surgery. Ann Thorac Surg (2008) 86:273-7. doi:10.1016/j.athoracsur.2007.06.001

27. McGurk M, Amis AA, Potamianos P, Goodger NM. Rapid prototyping techniques for anatomical modelling in medicine. Ann R Coll Surg Engl (1997) 79:169-74.

28. Sachs EM, Haggerty JS, Cima MJ, Williams PA. Three-Dimensional Printing Techniques. US Patent No. 5,204,055 (1993).

29. Watson RA. A low-cost surgical application of additive fabrication. J Surg Educ (2014) 71:14-7. doi:10.1016/j.jsurg.2013.10.012

30. Olszewski R, Szymor P, Kozakiewicz M. Accuracy of three-dimensional, paper-based models generated using a low-cost, three-dimensional printer. J Craniomaxillofac Surg (2014) 42(8):1847-52. doi:10.1016/j.jcms.2014.07.002
31. Crump SS. Apparatus and Method for Creating Three-Dimensional Objects. US Patent No. 5,121,329 (1992).

32. Dikovsky D, Napadensky E. Three-Dimensional Printing Process for Producing a Self-Destructible Temporary Structure. US Patent No. 8,470,231 (2013)

33. Chen Y, Niu F, Yu B, Liu J, Wang M, Gui L. Three-dimensional preoperative design of distraction osteogenesis for hemifacial microsomia. J Craniofac Surg (2014) 25:184-8. doi:10.1097/SCS.0000000000000391

34. Way TP, Barner KE. Automatic visual to tactile translation - part II: evaluation of the TACTile image creation system. IEEE Trans Rehabil Eng (1997) 5:95-105. doi:10.1109/86.559354

35. D'Urso PS, Barker TM, Earwaker WJ, Bruce LJ, Atkinson RL, Lanigan MW, et al. Stereolithographic biomodelling in cranio-maxillofacial surgery: a prospective trial.J Craniomaxillofac Surg (1999) 27:30-7. doi:10.1016/S1010-5182(99)80007-9

36. Guarino J, Tennyson S, McCain G, Bond L, Shea K, King H. Rapid prototyping technology for surgeries of the pediatric spine and pelvis: benefits analysis. $J$ Pediatr Orthop (2007) 27:955-60. doi:10.1097/bpo.0b013e3181594ced

37. Liu YF, Xu LW, Zhu HY, Liu SS. Technical procedures for template-guided surgery for mandibular reconstruction based on digital design and manufacturing. Biomed Eng Online (2014) 13:63. doi:10.1186/1475-925X-13-63

38. Tsai MJ, Wu CT. Study of mandible reconstruction using a fibula flap with application of additive manufacturing technology. Biomed Eng Online (2014) 13:57. doi:10.1186/1475-925X-13-57

39. Lim CG, Campbell DI, Clucas DM. Rapid prototyping technology in orbital floor reconstruction: application in three patients. Craniomaxillofac Trauma Reconstr (2014) 7:143-6. doi:10.1055/s-0034-1371080

40. Engel M, Hoffmann J, Castrillon-Oberndorfer G, Freudlsperger C. The value of three-dimensional printing modelling for surgical correction of orbital hypertelorism. Oral Maxillofac Surg (2014). doi:10.1007/s10006-014-0466-1

41. Azuma M, Yanagawa T, Ishibashi-Kanno N, Uchida F, Ito T, Yamagata K, et al. Mandibular reconstruction using plates prebent to fit rapid prototyping 3-dimensional printing models ameliorates contour deformity. Head Face Med (2014) 10:45. doi:10.1186/1746-160X-10-45

42. Jeong HS, Park KJ, Kil KM, Chong S, Eun HJ, Lee TS, et al. Minimally invasive plate osteosynthesis using 3D printing for shaft fractures of clavicles: technical note. Arch Orthop Trauma Surg (2014) 134:1551-5. doi:10.1007/s00402-014-2075-8

43. Tam MD, Laycock SD, Bell D, Chojnowski A. 3-D printout of a DICOM file to aid surgical planning in a 6 year old patient with a large scapular osteochondroma complicating congenital diaphyseal aclasia. J Radiol Case Rep (2012) 6:31-7. doi:10.3941/jrcr.v6i1.889

44. Schmauss D, Haeberle S, Hagl C, Sodian R. Three-dimensional printing in cardiac surgery and interventional cardiology: a single-centre experience. Eur J Cardiothorac Surg (2014). doi:10.1093/ejcts/ezu310

45. Witschey WR, Pouch AM, McGarvey JR, Ikeuchi K, Contijoch F, Levack MM, et al. Three-dimensional ultrasound-derived physical mitral valve modeling. Ann Thorac Surg (2014) 98:691-4. doi:10.1016/j.athoracsur.2014.04.094

46. Schmauss D, Gerber N, Sodian R. Three-dimensional printing of models for surgical planning in patients with primary cardiac tumors. J Thorac Cardiovasc Surg (2013) 145:1407-8. doi:10.1016/j.jtcvs.2012.12.030

47. Schmauss D, Schmitz C, Bigdeli AK, Weber S, Gerber N, Beiras-Fernandez A, et al. Three-dimensional printing of models for preoperative planning and simulation of transcatheter valve replacement. Ann Thorac Surg (2012) 93:e31-3. doi:10.1016/j.athoracsur.2011.09.031

48. Sodian R, Weber S, Markert M, Loeff M, Lueth T, Weis FC, et al. Pediatric cardiac transplantation: three-dimensional printing of anatomic models for surgical planning of heart transplantation in patients with univentricular heart. J Thorac Cardiovasc Surg (2008) 136:1098-9. doi:10.1016/j.jtcvs.2008.03.055

49. Sodian R, Schmauss D, Markert M, Weber S, Nikolaou K, Haeberle S, et al. Three-dimensional printing creates models for surgical planning of aortic valve replacement after previous coronary bypass grafting. Ann Thorac Surg (2008) 85:2105-8. doi:10.1016/j.athoracsur.2007.12.033

50. Markert M, Weber S, Lueth TC. A beating heart model 3D printed from specific patient data. Conf Proc IEEE Eng Med Biol Soc (2007) 2007:4472-5. doi:10.1109/ IEMBS.2007.4353332

51. Nakada T, Akiba T, Inagaki T, Morikawa T. Thoracoscopic anatomical subsegmentectomy of the right $\mathrm{S} 2 \mathrm{~b}+\mathrm{S} 3$ using a 3D printing model with rapid prototyping. Interact Cardiovasc Thorac Surg (2014) 19(4):696-8. doi:10.1093/ icvts/ivu174 
52. Akiba T, Inagaki T, Nakada T. Three-dimensional printing model of anomalous bronchi before surgery. Ann Thorac Cardiovasc Surg (2014) 20(Suppl):659-62. doi:10.5761/atcs.cr.13-00189

53. Tam MD, Laycock SD, Brown JR, Jakeways M. 3D printing of an aortic aneurysm to facilitate decision making and device selection for endovascular aneurysm repair in complex neck anatomy. J Endovasc Ther (2013) 20:863-7. doi:10.1583/13-4450MR.1

54. Hakansson A, Rantatalo M, Hansen T, Wanhainen A. Patient specific biomodel of the whole aorta - the importance of calcified plaque removal. Vasa (2011) 40:453-9. doi:10.1024/0301-1526/a000148

55. Sodian R, Schmauss D, Schmitz C, Bigdeli A, Haeberle S, Schmoeckel M, et al. 3-dimensional printing of models to create custom-made devices for coil embolization of an anastomotic leak after aortic arch replacement. Ann Thorac Surg (2009) 88:974-8. doi:10.1016/j.athoracsur.2009.03.014

56. Silberstein JL, Maddox MM, Dorsey P, Feibus A, Thomas R, Lee BR. Physical models of renal malignancies using standard cross-sectional imaging and 3-dimensional printers: a pilot study. Urology (2014) 84:268-72. doi:10.1016/j. urology.2014.03.042

57. Daniel M, Watson J, Hoskison E, Sama A. Frontal sinus models and onlay templates in osteoplastic flap surgery. Jaryngol Otol (2011) 125:82-5. doi:10.1017/ S0022215110001799

58. Suzuki M, Ogawa Y, Kawano A, Hagiwara A, Yamaguchi H, Ono H. Rapid prototyping of temporal bone for surgical training and medical education. Acta Otolaryngol (2004) 124:400-2. doi:10.1080/00016480410016478

59. Igami T, Nakamura Y, Hirose T, Ebata T, Yokoyama Y, Sugawara G, et al. Application of a three-dimensional print of a liver in hepatectomy for small tumors invisible by intraoperative ultrasonography: preliminary experience. World J Surg (2014) 38(12):3163-6. doi:10.1007/s00268-014-2740-7

60. Ikegami T, Maehara Y. Transplantation: 3D printing of the liver in living donor liver transplantation. Nat Rev Gastroenterol Hepatol (2013) 10:697-8. doi:10.1038/nrgastro.2013.195

61. Zein NN, Hanouneh IA, Bishop PD, Samaan M, Eghtesad B, Quintini C, et al. Three-dimensional print of a liver for preoperative planning in living donor liver transplantation. Liver Transpl (2013) 19:1304-10. doi:10.1002/lt.23729

62. Kang SH, Kim MK, Kim BC, Lee SH. Orthognathic Y-splint: a CAD/CAMengineered maxillary repositioning wafer assembly. Br J Oral Maxillofac Surg (2014) 52:667-9. doi:10.1016/j.bjoms.2014.01.023

63. Adolphs N, Liu W, Keeve E, Hoffmeister B. RapidSplint: virtual splint generation for orthognathic surgery - results of a pilot series. Comput Aided Surg (2014) 19:20-8. doi:10.3109/10929088.2014.887778

64. Cousley RR, Turner MJ. Digital model planning and computerized fabrication of orthognathic surgery wafers. J Orthod (2014) 41:38-45. doi:10.1179/146531 3313Y.0000000075

65. Kim BC, Lee CE, Park W, Kim MK, Zhengguo P, Yu HS, et al. Clinical experiences of digital model surgery and the rapid-prototyped wafer for maxillary orthognathic surgery. Oral Surg Oral Med Oral Pathol Oral Radiol Endod (2011) 111:278-85. doi:10.1016/j.tripleo.2010.04.038

66. Li B, Zhang L, Sun H, Yuan J, Shen SG, Wang X. A novel method of computer aided orthognathic surgery using individual CAD/CAM templates: a combination of osteotomy and repositioning guides. Br J Oral Maxillofac Surg (2013) 51:e239-44. doi:10.1016/j.bjoms.2013.03.007

67. Metzger MC, Hohlweg-Majert B, Schwarz U, Teschner M, Hammer B, Schmelzeisen R. Manufacturing splints for orthognathic surgery using a three-dimensional printer. Oral Surg Oral Med Oral Pathol Oral Radiol Endod (2008) 105:e1-7. doi:10.1016/j.tripleo.2007.07.040

68. D'Urso PS, Williamson OD, Thompson RG. Biomodeling as an aid to spinal instrumentation. Spine (Phila Pa 1976) (2005) 30:2841-5. doi:10.1097/01. brs.0000190886.56895.3d

69. Spottiswoode BS, van den Heever DJ, Chang Y, Engelhardt S, Du Plessis S, Nicolls F, et al. Preoperative three-dimensional model creation of magnetic resonance brain images as a tool to assist neurosurgical planning. Stereotact Funct Neurosurg (2013) 91:162-9. doi:10.1159/000345264

70. Fuller SM, Butz DR, Vevang CB, Makhlouf MV. Application of 3-dimensional printing in hand surgery for production of a novel bone reduction clamp. J Hand Surg Am (2014) 39:1840-5. doi:10.1016/j.jhsa.2014.06.009

71. Rankin TM, Giovinco NA, Cucher DJ, Watts G, Hurwitz B, Armstrong DG. Three-dimensional printing surgical instruments: are we there yet? J Surg Res (2014) 189:193-7. doi:10.1016/j.jss.2014.02.020
72. Waran V, Narayanan V, Karuppiah R, Owen SL, Aziz T. Utility of multimaterial 3D printers in creating models with pathological entities to enhance the training experience of neurosurgeons. J Neurosurg (2014) 120:489-92. doi:10.3171/2013.11.JNS131066

73. Abla AA, Lawton MT. Three-dimensional hollow intracranial aneurysm models and their potential role for teaching, simulation, and training. World Neurosurg (2014). doi:10.1016/j.wneu.2014.01.015

74. Mashiko T, Otani K, Kawano R, Konno T, Kaneko N, Ito Y, et al. Development of three-dimensional hollow elastic model for cerebral aneurysm clipping simulation enabling rapid and low cost prototyping. World Neurosurg (2013). doi:10.1016/j.wneu.2013.10.032

75. Wurm G, Tomancok B, Pogady P, Holl K, Trenkler J. Cerebrovascular stereolithographic biomodeling for aneurysm surgery. Technical note. J Neurosurg (2004) 100:139-45. doi:10.3171/jns.2004.100.1.0139

76. Wurm G, Lehner M, Tomancok B, Kleiser R, Nussbaumer K. Cerebrovascular biomodeling for aneurysm surgery: simulation-based training by means of rapid prototyping technologies. Surg Innov (2011) 18:294-306. doi:10.1177/1553350610395031

77. Waran V, Narayanan V, Karuppiah R, Thambynayagam HC, Muthusamy KA, Rahman ZA, et al. Neurosurgical endoscopic training via a realistic 3-dimensional model with pathology. Simul Healthc (2014). doi:10.1097/ SIH.0000000000000060

78. Costello JP, Olivieri LJ, Su L, Krieger A, Alfares F, Thabit O, et al. Incorporating three-dimensional printing into a simulation-based congenital heart disease and critical care training curriculum for resident physicians. Congenit Heart Dis (2014). doi:10.1111/chd.12238

79. Biglino G, Verschueren P, Zegels R, Taylor AM, Schievano S. Rapid prototyping compliant arterial phantoms for in-vitro studies and device testing.J Cardiovasc Magn Reson (2013) 15:2. doi:10.1186/1532-429X-15-2

80. Bustamante S, Bose S, Bishop P, Klatte R, Norris F. Novel application of rapid prototyping for simulation of bronchoscopic anatomy. J Cardiothorac Vasc Anesth (2014) 28:1134-7. doi:10.1053/j.jvca.2013.08.015

81. Cheung CL, Looi T, Lendvay TS, Drake JM, Farhat WA. Use of 3-dimensional printing technology and silicone modeling in surgical simulation: development and face validation in pediatric laparoscopic pyeloplasty. J Surg Educ (2014) 71:762-7. doi:10.1016/j.jsurg.2014.03.001

82. Li J, Hsu Y, Luo E, Khadka A, Hu J. Computer-aided design and manufacturing and rapid prototyped nanoscale hydroxyapatite/polyamide (n-HA/PA) construction for condylar defect caused by mandibular angle ostectomy. Aesthetic Plast Surg (2011) 35:636-40. doi:10.1007/s00266-010-9602-y

83. Klammert U, Gbureck U, Vorndran E, Rodiger J, Meyer-Marcotty P, Kubler AC. $3 \mathrm{D}$ powder printed calcium phosphate implants for reconstruction of cranial and maxillofacial defects. J Craniomaxillofac Surg (2010) 38:565-70. doi:10.1016/j. jcms.2010.01.009

84. Saijo H, Igawa K, Kanno Y, Mori Y, Kondo K, Shimizu K, et al. Maxillofacial reconstruction using custom-made artificial bones fabricated by inkjet printing technology. J Artif Organs (2009) 12:200-5. doi:10.1007/s10047-009-0462-7

85. Wurm G, Tomancok B, Holl K, Trenkler J. Prospective study on cranioplasty with individual carbon fiber reinforced polymer (CFRP) implants produced by means of stereolithography. Surg Neurol (2004) 62:510-21. doi:10.1016/j. surneu.2004.01.025

86. D'Urso PS, Earwaker WJ, Barker TM, Redmond MJ, Thompson RG, Effeney DJ, et al. Custom cranioplasty using stereolithography and acrylic. Br J Plast Surg (2000) 53:200-4. doi:10.1054/bjps.1999.3268

87. Bicanic G, Barbaric K, Bohacek I, Aljinovic A, Delimar D. Current concept in dysplastic hip arthroplasty: techniques for acetabular and femoral reconstruction. World J Orthop (2014) 5:412-24. doi:10.5312/wjo.v5.i4.412

88. Koulouvaris P, Stafylas K, Sculco T, Xenakis T. Distal femoral shortening in total hip arthroplasty for complex primary hip reconstruction. A new surgical technique. J Arthroplasty (2008) 23:992-8. doi:10.1016/j.arth.2007.09.013

89. Zopf DA, Hollister SJ, Nelson ME, Ohye RG, Green GE. Bioresorbable airway splint created with a three-dimensional printer. NEngl J Med (2013) 368:2043-5. doi:10.1056/NEJMc1206319

90. Reeves P. Additive manufacturing \& 3D printing medical \& healthcare: a new industrial perspective. The 3D Printing \& Additive Manufacturing People. Derbyshire (2014).

91. Wozniak K, Rzepecka-Wozniak E, Moskala A, Pohl J, Latacz K, Dybala B. Weapon identification using antemortem computed tomography with virtual $3 \mathrm{D}$ and rapid 
prototype modeling - a report in a case of blunt force head injury. Forensic Sci Int (2012) 222:e29-32. doi:10.1016/j.forsciint.2012.06.012

92. McMenamin PG, Quayle MR, McHenry CR, Adams JW. The production of anatomical teaching resources using three-dimensional (3D) printing technology. Anat Sci Educ (2014) 7:479-86. doi:10.1002/ase.1475

93. Giovinco NA, Dunn SP, Dowling L, Smith C, Trowell L, Ruch JA, et al. A novel combination of printed 3-dimensional anatomic templates and computer-assisted surgical simulation for virtual preoperative planning in Charcot foot reconstruction. J Foot Ankle Surg (2012) 51:387-93. doi:10.1053/j.jfas.2012.01.014

94. Groth C, Kravitz ND, Jones PE, Graham JW, Redmond WR. Three-dimensional printing technology. J Clin Orthod (2014) 48:475-85.

95. Chen J, Zhang Z, Chen X, Zhang C, Zhang G, Xu Z. Design and manufacture of customized dental implants by using reverse engineering and selective laser melting technology. J Prosthet Dent (2014) 112:1088-95. doi:10.1016/j. prosdent.2014.04.026

96. Flugge TV, Nelson K, Schmelzeisen R, Metzger MC. Three-dimensional plotting and printing of an implant drilling guide: simplifying guided implant surgery. J Oral Maxillofac Surg (2013) 71:1340-6. doi:10.1016/j.joms.2013.04.010

97. Goyanes A, Buanz AB, Hatton GB, Gaisford S, Basit AW. 3D printing of modified-release aminosalicylate (4-ASA and 5-ASA) tablets. Eur J Pharm Biopharm (2014). doi:10.1016/j.ejpb.2014.12.003

98. Skowyra J, Pietrzak K, Alhnan MA. Fabrication of extended-release patient-tailored prednisolone tablets via fused deposition modelling (FDM) 3D printing. Eur J Pharm Sci (2014) 68C:11-7. doi:10.1016/j.ejps.2014.11.009

99. Lueders C, Jastram B, Hetzer R, Schwandt H. Rapid manufacturing techniques for the tissue engineering of human heart valves. Eur J Cardiothorac Surg (2014) 46:593-601. doi:10.1093/ejcts/ezt510

100. Chang JW, Park SA, Park JK, Choi JW, Kim YS, Shin YS, et al. Tissue-engineered tracheal reconstruction using three-dimensionally printed artificial tracheal graft: preliminary report. Artif Organs (2014) 38:E95-105. doi:10.1111/aor.12310

101. Lee Ventola C. Medical applications for $3 \mathrm{D}$ printing: current and projected uses. P T (2014) 39:704-11.

102. Fullerton JN, Frodsham GC, Day RM. 3D printing for the many, not the few. Nat Biotechnol (2014) 32:1086-7. doi:10.1038/nbt.3056

103. Hieu LC, Zlatov N, Vander Sloten J, Bohez E, Khanh L, Binh PH, et al. Medical rapid prototyping applications and methods. Assemb Autom (2005) 25:284-92. doi:10.1108/01445150510626415

104. Rosset A, Spadola L, Ratib O. OsiriX: an open-source software for navigating in multidimensional DICOM images. J Digit Imaging (2004) 17:205-16. doi:10.1007/s10278-004-1014-6

105. Fedorov A, Beichel R, Kalpathy-Cramer J, Finet J, Fillion-Robin JC, Pujol S, et al. $3 \mathrm{D}$ slicer as an image computing platform for the quantitative imaging network. Magn Reson Imaging (2012) 30:1323-41. doi:10.1016/j.mri.2012.05.001

106. Gering DT, Nabavi A, Kikinis R, Hata N, O’Donnell LJ, Grimson WE, et al. An integrated visualization system for surgical planning and guidance using image fusion and an open MR. J Magn Reson Imaging (2001) 13:967-75. doi:10.1002/ jmri.1139

107. Golby AJ, Kindlmann G, Norton I, Yarmarkovich A, Pieper S, Kikinis R. Interactive diffusion tensor tractography visualization for neurosurgical planning. Neurosurgery (2011) 68:496-505. doi:10.1227/NEU.0b013e3182061ebb

108. Chae MP, Hunter-Smith DJ, Spychal RT, Rozen WM. 3D volumetric analysis for planning breast reconstructive surgery. Breast Cancer Res Treat (2014) 146(2):457-60. doi:10.1007/s10549-014-3028-1

109. Chae MP, Lin F, Spychal RT, Hunter-Smith DJ, Rozen WM. 3D-printed haptic "reverse" models for preoperative planning in soft tissue reconstruction: a case report. Microsurgery (2014). doi:10.1002/micr.22293

110. Ibrahim D, Broilo TL, Heitz C, de Oliveira MG, de Oliveira HW, Nobre SM, et al. Dimensional error of selective laser sintering, three-dimensional printing and PolyJet models in the reproduction of mandibular anatomy. J Craniomaxillofac Surg (2009) 37:167-73. doi:10.1016/j.jcms.2008.10.008

111. Silva DN, Gerhardt de Oliveira M, Meurer E, Meurer MI, Lopes da Silva JV, Santa-Barbara A. Dimensional error in selective laser sintering and 3D-printing of models for craniomaxillary anatomy reconstruction. J Craniomaxillofac Surg (2008) 36:443-9. doi:10.1016/j.jcms.2008.04.003

112. Fitzwater KL, Marcellin-Little DJ, Harrysson OL, Osborne JA, Poindexter EC. Evaluation of the effect of computed tomography scan protocols and freeform fabrication methods on bone biomodel accuracy. Am J Vet Res (2011) 72:1178-85. doi:10.2460/ajvr.72.9.1178
113. Bos EJ, Scholten T, Song Y, Verlinden JC, WolffJ, Forouzanfar T, et al. Developing a parametric ear model for auricular reconstruction: a new step towards patient-specific implants. JCraniomaxillofac Surg (2015) 43:390-5. doi:10.1016/j. jcms.2014.12.016

114. Nishimoto S, Sotsuka Y, Kawai K, Fujita K, Kakibuchi M. Three-dimensional mock-up model for chondral framework in auricular reconstruction, built with a personal three-dimensional printer. Plast Reconstr Surg (2014) 134:180e-1e. doi: 10.1097/PRS.0000000000000263

115. Xu Y, Fan F, Kang N, Wang S, You J, Wang H, et al. Tissue engineering of human nasal alar cartilage precisely by using three-dimensional printing. Plast Reconstr Surg (2015) 135:451-8. doi:10.1097/PRS.0000000000000856

116. Cabalag MS, Chae MP, Miller GS, Rozen WM, Hunter-Smith DJ. Use of three-dimensional printed 'haptic' models for preoperative planning in an Australian plastic surgery unit. ANZ J Surg (2015). doi:10.1111/ans.13168

117. Garcia Tutor E, Romeo M, Chae MP, Hunter-Smith DJ, Rozen WM. 3D volumetric modeling and microvascular reconstruction of irradiated lumbosacral defects after oncologic resection. J Reconstr Microsurg (2015).

118. Gillis JA, Morris SF. Three-dimensional printing of perforator vascular anatomy. Plast ReconstrSurg (2014) 133:80e-2e. doi:10.1097/01.prs.0000436523.79293.64

119. Chae MP, Hunter-Smith DJ, De-Silva I, Tham S, Spychal RT, Rozen WM. Fourdimensional (4D) printing: a new evolution in computed tomography-guided stereolithographic modeling. Principles and application. J Reconstr Microsurg (2015). doi:10.1055/s-0035-1549006

120. Sutradhar A, Park J, Carrau D, Miller MJ. Experimental validation of 3D printed patient-specific implants using digital image correlation and finite element analysis. Comput Biol Med (2014) 52:8-17. doi:10.1016/j.compbiomed.2014.06.002

121. Ciocca L, De Crescenzio F, Fantini M, Scotti R. Rehabilitation of the nose using CAD/CAM and rapid prototyping technology after ablative surgery of squamous cell carcinoma: a pilot clinical report. Int J Oral Maxillofac Implants (2010) 25:808-12. doi:10.1080/10255840903251304

122. Ciocca L, De Crescenzio F, Fantini M, Scotti R. CAD/CAM bilateral ear prostheses construction for Treacher Collins syndrome patients using laser scanning and rapid prototyping. Comput Methods Biomech Biomed Engin (2010) 13:379-86. doi:10.1080/10255840903251304

123. Rozen WM, Chubb D, Grinsell D, Ashton MW. Computed tomographic angiography: clinical applications. Clin Plast Surg (2011) 38:229-39. doi:10.1016/j. cps.2011.03.007

124. Rozen WM, Garcia-Tutor E, Alonso-Burgos A, Acosta R, Stillaert F, Zubieta $\mathrm{JL}$, et al. Planning and optimising DIEP flaps with virtual surgery: the Navarra experience. J Plast Reconstr Aesthet Surg (2010) 63:289-97. doi:10.1016/j. bjps.2008.10.007

125. Donfrancesco A, Montemurro P, Heden P. Three-dimensional simulated images in breast augmentation surgery: an investigation of patients' satisfaction and the correlation between prediction and actual outcome. Plast Reconstr Surg (2013) 132:810-22. doi:10.1097/PRS.0b013e3182a014cb

126. Rozen WM, Ashton MW. Modifying techniques in deep inferior epigastric artery perforator flap harvest with the use of preoperative imaging. ANZ J Surg (2009) 79:598-603. doi:10.1111/j.1445-2197.2009.05013.x

127. Rozen WM, Ashton MW, Le Roux CM, Pan WR, Corlett RJ. The perforator angiosome: a new concept in the design of deep inferior epigastric artery perforator flaps for breast reconstruction. Microsurgery (2010) 30:1-7. doi:10.1002/ micr.20684

128. Lee JW, Fang JJ, Chang LR, Yu CK. Mandibular defect reconstruction with the help of mirror imaging coupled with laser stereolithographic modeling technique. J Formos Med Assoc (2007) 106:244-50. doi:10.1016/S0929-6646(09)60247-3

129. Cao D, Yu Z, Chai G, Liu J, Mu X. Application of EH compound artificial bone material combined with computerized three-dimensional reconstruction in craniomaxillofacial surgery. J Craniofac Surg (2010) 21:440-3. doi:10.1097/ SCS.0b013e3181cfe9bc

130. Katsuragi Y, Kayano S, Akazawa S, Nagamatsu S, Koizumi T, Matsui T, et al. Mandible reconstruction using the calcium-sulphate three-dimensional model and rubber stick: a new method, 'mould technique', for more accurate, efficient and simplified fabrication. J Plast Reconstr Aesthet Surg (2011) 64:614-22. doi:10.1016/j.bjps.2010.08.010

131. Hsieh MK, Chen AC, Cheng CY, Chou YC, Chan YS, Hsu KY. Repositioning osteotomy for intra-articular malunion of distal radius with radiocarpal and/ or distal radioulnar joint subluxation. J Trauma (2010) 69:418-22. doi:10.1097/ TA.0b013e3181ca0834 
132. Gan Y, Xu D, Lu S, Ding J. Novel patient-specific navigational template for total knee arthroplasty. Comput Aided Surg (2011) 16:288-97. doi:10.3109/1092908 8.2011.621214

133. Kunz M, Ma B, Rudan JF, Ellis RE, Pichora DR. Image-guided distal radius osteotomy using patient-specific instrument guides. J Hand Surg Am (2013) 38:1618-24. doi:10.1016/j.jhsa.2013.05.018

134. Kataoka T, Oka K, Miyake J, Omori S, Tanaka H, Murase T. 3-Dimensional prebent plate fixation in corrective osteotomy of malunited upper extremity fractures using a real-sized plastic bone model prepared by preoperative computer simulation. J Hand Surg Am (2013) 38:909-19. doi:10.1016/j. jhsa.2013.02.024

135. Minns RJ, Bibb R, Banks R, Sutton RA. The use of a reconstructed threedimensional solid model from CT to aid the surgical management of a total knee arthroplasty: a case study. Med Eng Phys (2003) 25:523-6. doi:10.1016/ S1350-4533(03)00050-X

136. Reinhardt JM, Ding K, Cao K, Christensen GE, Hoffman EA, Bodas SV. Registration-based estimates of local lung tissue expansion compared to xenon CT measures of specific ventilation. Med Image Anal (2008) 12:752-63. doi:10.1016/j.media.2008.03.007

137. Chang JY, Li QQ, Xu QY, Allen PK, Rebueno N, Gomez DR, et al. Stereotactic ablative radiation therapy for centrally located early stage or isolated parenchymal recurrences of non-small cell lung cancer: how to fly in a "no fly zone". Int J Radiat Oncol Biol Phys (2014) 88:1120-8. doi:10.1016/j.ijrobp.2014.01.022

138. Kontio R, Bjorkstrand R, Salmi M, Paloheimo M, Paloheimo KS, Tuomi J, et al. Designing and additive manufacturing a prototype for a novel instrument for mandible fracture reduction. Surgery (2012) S1:002. doi:10.4172/2161-1076. S1-002

139. Sugawara T, Higashiyama N, Kaneyama S, Takabatake M, Watanabe N, Uchida F, et al. Multistep pedicle screw insertion procedure with patient-specific lamina fit-and-lock templates for the thoracic spine: clinical article. J Neurosurg Spine (2013) 19:185-90. doi:10.3171/2013.4.SPINE121059

140. Lambrecht JT, Berndt DC, Schumacher R, Zehnder M. Generation of threedimensional prototype models based on cone beam computed tomography. Int J Comput Assist Radiol Surg (2009) 4:175-80. doi:10.1007/s11548-008-0275-9

141. Kimura T, Morita A, Nishimura K, Aiyama H, Itoh H, Fukaya S, et al. Simulation of and training for cerebral aneurysm clipping with 3-dimensional models. Neurosurgery (2009) 65:719-25. doi:10.1227/01.NEU.0000354350.88899.07

142. Chueh JY, Wakhloo AK, Gounis MJ. Neurovascular modeling: small-batch manufacturing of silicone vascular replicas. AJNR Am J Neuroradiol (2009) 30:1159-64. doi:10.3174/ajnr.A1543

143. Sulaiman A, Boussel L, Taconnet F, Serfaty JM, Alsaid H, Attia C, et al. In vitro non-rigid life-size model of aortic arch aneurysm for endovascular prosthesis assessment. Eur J Cardiothorac Surg (2008) 33:53-7. doi:10.1016/j. ejcts.2007.10.016

144. Kalejs M, von Segesser LK. Rapid prototyping of compliant human aortic roots for assessment of valved stents. Interact Cardiovasc Thorac Surg (2009) 8:182-6. doi:10.1510/icvts.2008.194134

145. Armillotta A, Bonhoeffer P, Dubini G, Ferragina S, Migliavacca F, Sala G, et al. Use of rapid prototyping models in the planning of percutaneous pulmonary valved stent implantation. Proc Inst Mech Eng H (2007) 221:407-16. doi:10.1243/09544119JEIM83

146. Bruyere F, Leroux C, Brunereau L, Lermusiaux P. Rapid prototyping model for percutaneous nephrolithotomy training. JEndourol (2008) 22:91-6. doi:10.1089/ end.2007.0025

147. Kim MS, Sbalchiero JC, Reece GP, Miller MJ, Beahm EK, Markey MK. Assessment of breast aesthetics. Plast Reconstr Surg (2008) 121:186e-94e. doi:10.1097/01. prs.0000304593.74672.b8
148. Chan YC, Qing KX, Cheng SW. Custom-made fenestrated stent grafts to preserve accessory renal arteries in patients with abdominal aortic aneurysms. Acta Chir Belg (2014) 114:183-8.

149. Hourfar J, Kanavakis G, Goellner P, Ludwig B. Fully customized placement of orthodontic miniplates: a novel clinical technique. Head Face Med (2014) 10:14. doi:10.1186/1746-160X-10-14

150. Lee SJ, Lee HP, Tse KM, Cheong EC, Lim SP. Computer-aided design and rapid prototyping-assisted contouring of costal cartilage graft for facial reconstructive surgery. Craniomaxillofac Trauma Reconstr (2012) 5:75-82. doi:10.105 5/s-0031-1300964

151. Wu G, Zhou B, Bi Y, Zhao Y. Selective laser sintering technology for customized fabrication of facial prostheses. J Prosthet Dent (2008) 100:56-60. doi:10.1016/ S0022-3913(08)60138-9

152. Sykes LM, Parrott AM, Owen CP, Snaddon DR. Applications of rapid prototyping technology in maxillofacial prosthetics. Int J Prosthodont (2004) 17:454-9.

153. Subburaj K, Nair C, Rajesh S, Meshram SM, Ravi B. Rapid development of auricular prosthesis using $\mathrm{CAD}$ and rapid prototyping technologies. Int J Oral Maxillofac Surg (2007) 36:938-43. doi:10.1016/j.ijom.2007.07.013

154. Karayazgan-Saracoglu B, Gunay Y, Atay A. Fabrication of an auricular prosthesis using computed tomography and rapid prototyping technique. J Craniofac Surg (2009) 20:1169-72. doi:10.1097/SCS.0b013e3181acdb95

155. De Crescenzio F, Fantini M, Ciocca L, Persiani F, Scotti R. Design and manufacturing of ear prosthesis by means of rapid prototyping technology. Proc Inst Mech Eng H (2011) 225:296-302. doi:10.1243/09544119JEIM856

156. Ciocca L, Scotti R. Oculo-facial rehabilitation after facial cancer removal: updated CAD/CAM procedures. A pilot study. Prosthet Orthot Int (2013). doi: $10.1177 / 0309364613512368$

157. Xie P, Hu Z, Zhang X, Li X, Gao Z, Yuan D, et al. Application of 3-dimensional printing technology to construct an eye model for fundus viewing study. PLoS One (2014) 9:e109373. doi:10.1371/journal.pone.0109373

158. Tsuji M, Noguchi N, Ihara K, Yamashita Y, Shikimori M, Goto M. Fabrication of a maxillofacial prosthesis using a computer-aided design and manufacturing system. J Prosthodont (2004) 13:179-83. doi:10.1111/j.1532-849X.2004. 04029.x

159. Fantini M, De Crescenzio F, Ciocca L. Design and rapid manufacturing of anatomical prosthesis for facial rehabilitation. Int J Interact Des Manuf (2013) 7:51-62. doi:10.1007/s12008-012-0159-7

160. De Laurentis KJ, Mavroidis C. Mechanical design of a shape memory alloy actuated prosthetic hand. Technol Health Care (2002) 10:91-106.

161. Eppley BL. Craniofacial reconstruction with computer-generated HTR patientmatched implants: use in primary bony tumor excision. J Craniofac Surg (2002) 13:650-7. doi:10.1097/00001665-200209000-00011

162. Sammartino G, Della Valle A, Marenzi G, Gerbino S, Martorelli M, di Lauro AE, et al. Stereolithography in oral implantology: a comparison of surgical guides. Implant Dent (2004) 13:133-9. doi:10.1097/01.ID.0000127526.36938.4C

Conflict of Interest Statement: The authors declare that the research was conducted in the absence of any commercial or financial relationships that could be construed as a potential conflict of interest.

Copyright (C) 2015 Chae, Rozen, McMenamin, Findlay, Spychal and Hunter-Smith. This is an open-access article distributed under the terms of the Creative Commons Attribution License (CC BY). The use, distribution or reproduction in other forums is permitted, provided the original author(s) or licensor are credited and that the original publication in this journal is cited, in accordance with accepted academic practice. No use, distribution or reproduction is permitted which does not comply with these terms. 